\title{
Electric Power System Planning under Uncertainty Using Inexact Inventory Nonlinear Programming Method
}

\author{
M. Q. Suo ${ }^{1}$, Y. P. Li ${ }^{1, *}$, G. H. Huang ${ }^{1}$, D. L. Deng ${ }^{2}$ and Y. F. $\mathrm{Li}^{1}$ \\ ${ }^{1}$ MOE Key Laboratory of Regional Energy Systems Optimization, Sino-Canada Energy and Environmental Research Academy, North China \\ Electric Power University, Beijing 102206, China \\ ${ }^{2}$ Department of Mathematics and Statistics, University of Regina, Regina, Sask. S4S 0A2, Canada
}

Received 9 May 2012; revised 25 December 2012; accepted 11 January 2013; published online 25 September 2013

\begin{abstract}
In this study, an inexact inventory nonlinear programming (IINP) model is proposed for supporting electric power system planning under multiple unit prices and uncertain demands. The proposed IINP can deal with uncertainties presented as intervals and address nonlinearities in the objective function. It can also help to solve material supply problem with diverse unit prices as well as what, where, when and how much material should be purchased under uncertainty. Then, the IINP is applied to a case study of energy resources supply planning for an electric power system. Results obtained are useful for supporting (a) determination of reasonable energy resources supply scheme with global solutions, and elimination of step by step comparisons among many purchase schemes, (b) adjustment or justification purchase batches of energy resources supply and facility expansion for power-conversion technologies under different demand levels, and (c) integration of policies regarding energy resources supply, economy objective and environmental protection for in-depth analysis of tradeoff between purchase batch and unit price as well as system cost and risk.
\end{abstract}

Keywords: energy resources supply, interval, inventory, nonlinear, 0-1 integer, piecewise

\section{Introduction}

With the rapid economic development and continual urban expansion, electricity demand is increasing sharply while energy resources are decreasing severely throughout the world. For example, according to Statistics Bureau of Handan (Handan Statistics Bureau, 2011), the capacity expansion of electric power system in the city of Handan in China was 45.22 GW from 2003 to 2010. However, the reduced quantity of coal reserves was 300 million tonne from 2003 to 2010 . To effectively address this problem, a series of processes should be considered synthetically: energy resources supply, transportation, storage, conversion and consumption as well as social policies. Each of them contains a variety of complexities, such as the diversity of available resource quantity and quality, multiple transportation tools and storage options, different conversion technologies and air pollution control schemes. Moreover, these complexities can be multiplied by many uncertainties expressed as diverse formats and their interactions. Therefore, effective planning of electricity generation processes and efficient reflection of these complexities are critical to deal with electricity demand from a long-term point of view.

* Corresponding author. Tel.: +86 10 51971255; fax: +86 1051971284 .

E-mail address: yongping.li@iseis.org (Y. P. Li).

ISSN: $1726-2135$ print/1684-8799 online

(C) 2013 ISEIS All rights reserved. doi:10.3808/jei.201300245
Previously, a number of systems analysis approaches were conducted to address the above problems in electric power systems (e.g., energy resources supply, conversion and demand). For example, with respect to energy resources supply, a great number of researchers encompassed different statistical analysis and simulation technologies to assess and estimate the current resources status and future allowance based on historic data (Laherrere, 2001, 2004; Rempel et al., 2006; Birant, 2011; Dale, 2012); relating to energy resources conversion, techniques based on optimization and decision analysis were proposed to solve problems such as capacity expansion (Hsu et al., 2000; Ahmed and Sahinidis, 2003; Yang and Wen, 2005; Yang et al., 2010; Suo et al., 2012; Xiong et al., 2012), improvement of generation efficiency (Dong et al., 2005; Wiszniewski, 2007; Nikolaidis and Vournas, 2008; Fallahi et al., 2011), reduction of air pollutants (Lazaroiu et al., 2007; Li et al., 2010; Zhou et al., 2011; Zhou et al., 2012), and combination with climate change (Rubin et al., 2004; Jafar et al., 2008; Muis et al., 2010; Shen et al., 2012); regarding electricity demand, many models were developed to estimate and forecast the electricity demand in different temporal and spatial scales, such as time series models (Tripathy, 1997; Hunt et al., 2003; Kumar and Jain, 2010), regression models (Jannuzzi and Schipper, 1991; Tunc et al., 2006; Jónsson et al., 2010), econometric models (Arsenault et al., 1995; Christodoulakis et al., 2000; Meng and Niu, 2011), decomposition models (Lean and Smyth, 2009; Lazzaretto et al., 2010; Afshar and Bigdeli, 2011) and artificial systems 
(Hsu and Chen, 2003; Carpinteiro et al., 2007; Xia et al., 2010). However, few models consider energy resources supply with different unit prices under varied spatial and temporal conditions as well as its association with resources transporttation, storage, conversion and environment. In fact, different unit prices for energy resources supply are usually in accordance with varied purchase quantities (whether the purchase amount or the purchase batch per time), which could lead to a variety of purchase schemes. Combining with the energy resources limitation in varied regions, different purchase schemes can bring significant influence in resources transportation scheme, storage management, conversion structure and scale as well as surrounding environmental quality in electric power systems. In this case, several questions have to be answered by the decision makers: (a) what energy resources should be purchased, (b) where resources should be purchased from, local and/or other regions, (c) which scheme/unit price should be selected, (d) when and how much energy resources should be purchased.

An attractive technique that could tackle the above problems is inventory theory, which was launched to address the material supply problem with diverse unit prices, as well as to solve what, where, when and how much material should be purchased under multiple materials, multiple unit prices and multiple demand levels with minimized system cost or maximized system profit. In the past decades, a number of methods based on inventory theory were developed for industrial production management (Hammami et al., 2003; Kukreja and Schmidt, 2005; Porras and Dekker, 2008; EI Saadany and Jaber, 2010) and economic operation management (Khouja, 2001; Papachristos and Skouri, 2003; Shin and Benton, 2007; Wang and Yang, 2009; Rieksts and Ventura, 2010). For example, Wee and Yang (2004) developed a heuristic solution model for a producer-distributors-retailers inventory system using the principle of strategic partnership, where the integration of the supply chain was considered to reduce system cost; Gupta et al. (2006) presented a discrete-time model for setting clearance prices to clear retail inventories of fashion goods, where a heuristic procedure was developed to find near-optimal prices; Kim and Hwang (2008) dealt with an incremental discount policy on the taxi fare by developing a mathematical model based on regenerative process, with the assumption that customers arrive following a Poisson process with price-sensitive arrival rates; Arnold et al. (2009) presented a deterministic optimal control approach optimizing the procurement and inventory policy of an enterprise that is processing a raw material when the purchasing price, holding cost and the demand rate fluctuating over time; Suo et al. (2011) developed an inventory-theory-based inexact two-stage model for solving water shortage and allocation problems under different flow levels; Tsao and Lu (2012) addressed an integrated facility location and inventory allocation problem through considering two types of transportation cost discounts: quantity discounts for inbound transportation cost and distance discounts for outbound transportation cost. However, in these methods, neural network and/or genetic algorithm were used to get the best purchase scheme, with time consuming calculations and difficulties in obtaining global solutions under uncertainty. In fact, in electric power systems, due to the diversity of supply technology options available (affecting model size and complexity), the temporal and/or spatial evolutions of parameters over medium- to long-term time horizons, the dynamic variation of systems' conditions, the environmental and social arguments, various uncertainties and nonlinearities may exist in a variety of system components during the planning process (Li et al., 2010). Unfortunately, few studies were focused on developing inventory theory models for electric-power systems planning under uncertainty.

Therefore, this study is to develop an inexact inventory nonlinear programming (IINP) model for identifying multiple energy resources supply schemes and supporting electric power systems planning under uncertainty. The IINP will couple interval-parameter programming (IPP) with inventory nonlinear programming (INP), such that uncertainties presented as interval values and nonlinearities in the objective function can be addressed. The developed model will be first linearized by a $0 \sim 1$ piecewise linearization approach, and then be transformed into two deterministic submodels based on an interactive algorithm. A case study of energy resources supply planning for an electric power system will be provided to illustrate the applicability of the proposed method. Different energy resources supply schemes and the relationship with resources transportation, storage, conversion as well as environmental policy will be analyzed by IINP, such that optimal purchase schemes for energy resources can be identified to realize a minimum system cost under uncertainty.

\section{Methodology}

\subsection{Inexact Inventory Nonlinear Programming}

Firstly, a description of a quantity discount inventory problem in inventory theory is provided in this section. The most common quantity discount inventory problem faced by manufacturers, retailers, and wholesalers is that the unit price of one material is varied with its purchase batch (i.e. if the purchase batch is different, the unit price may be also different even for the same material). There are many options followed with different unit prices and purchase batches, and the more the purchase is, the lower the unit price is (i.e. economies of scale). Under some situations, the unit price of the exceeding limit part is to increase because of the limit supply. Different purchase batches may lead to varied purchase schemes. Therefore, an inventory nonlinear programming (INP) model is formulated to solve such problems, where the unit price could change with the purchase batch.

Specifically, the INP model can be described as follows: assuming that one material is needed to be purchased and there is no shortage. The related components include: demand (unit/unit time), setup cost for ordering one batch (\$), unit cost for producing or purchasing each unit (\$/unit), holding cost per unit per unit of time held in inventory (\$/unit time), purchasing batch (unit/time), and time period (day or month). In detail, the demand means the total demand quantity in a 
unit time; the setup cost means the cost for ordering one batch to replenish the stock, including the handling charge (the expenses for clients), communication expense, and travelling expense (all the fees happened for handling official business during the travelling period, such as transportation, accommodation and others) occurred in the ordering process; the unit cost includes the cost for ordering or purchasing one material; holding cost means the cost of storage's operation, insurance and protection and so on; time period means a cycle length from one purchase scheme to the next scheme, and equals to purchasing batch divided by demand and then multiplied by the unit time, which can be used to determine when to purchase a kind of material. If the time period is $t$, the serial purchase schemes can be carried out one by one after each $t$ time. Let the demand and batch be $X$ and $Q$ units per unit time, respecttively. The setup cost for purchasing one batch and the holding cost per unit per unit of time held in inventory are $K(\$)$ and $H$ (\$/month), respectively. Its corresponding unit cost is $C(Q)$ (\$/unit), which is a piecewise function. When $Q_{i-1} \leq Q \leq Q_{i}$, $C\left(Q_{i}\right)=C_{i}(i=1,2, \ldots, n)$, where $C\left(Q_{i}\right)$ is a piecewise constant function and $Q_{i}$ is the demarcation point of thprice discount, with the assumption that $0 \leq Q_{0}<Q_{1}<\cdots<Q_{n}$ and $C_{1}>C_{2}>\cdots>C_{n}$.

Then, the total cost function of quantity discount inventtory in one period, denoted by $f(Q)$, can be formulated as follows:

$$
f(Q)=X C_{i}+1 / 2 H Q+K X / Q,\left(Q_{i-1} \leq Q<Q_{i} ; i=1,2, \ldots, n\right)
$$

By setting the first derivative of $f(Q)$ to zero (and noting that the second derivative is positive), it can be obtained that

$$
\begin{aligned}
& \partial f / \partial Q=1 / 2 H-K X / Q^{2} \\
& Q^{*}=\sqrt{2 K X / H} \\
& f\left(Q^{*}\right)=X C_{i}^{*}+1 / 2 H Q^{*}+K X / Q^{*}=\sqrt{2 K H X}+X C_{i}
\end{aligned}
$$

where $C_{i}^{*}$ is the unit price when $Q^{*}$ is included in its corresponding interval. However, the total cost in Equation (4) may not be a minimum one. Because of the quantity discount, it is necessary to calculate the total cost in other intervals, in order to obtain the optimum solution. Therefore, the optimum solution of $f$ should be chosen between $f\left(Q_{i}\right)$ and $f\left(Q^{*}\right)$, which can be defined as follows:

$$
f^{*}\left(Q^{*}\right)=\min \left\{f\left(Q_{i}\right), f\left(Q^{*}\right) \mid i=1,2, \cdots, n\right\}
$$

Under this condition, binary variables are introduced into Equation (5) to solve the quantity discount problem in supply systems, which leads to an inventory nonlinear programming (INP) model. The general formulation with the objective to be minimized can be expressed as follows:

$$
\begin{aligned}
\operatorname{Min} f & =\sum_{i=1}^{m}\left(x_{i j} C_{i j^{\prime}}\left(Q_{i j^{\prime}}\right)+\sqrt{2 K_{i} H_{i} x_{i j^{\prime}}}\right)+\sum_{i=1}^{m} \sum_{j=1, j \neq j^{\prime}}^{n}\left(x_{i j} C_{i j}\left(Q_{i j}\right)\right. \\
& \left.+1 / 2 H_{i} Q_{i j} y_{i j}+K_{i} x_{i} / Q_{i j}\right)
\end{aligned}
$$

subject to:

$$
\begin{aligned}
& \sum_{i=1}^{m} a_{i l} x_{i} \geq b_{l}, l=1,2, \ldots, r \\
& C_{i j^{\prime}}\left(Q_{i j^{\prime}}\right)=C_{i j^{\prime}}, C_{i j-1}\left(Q_{i j-1}\right)>C_{i j^{\prime}}\left(Q_{i j^{\prime}}\right)>C_{i j}\left(Q_{i j}\right), \\
& \text { if } Q_{i j-1} \leq Q_{i j^{\prime}}<Q_{i j}, \forall i, j \neq j^{\prime} \\
& Q_{i j^{\prime}}=\sqrt{2 K_{i} x_{i j^{\prime}} / H_{i}}, \forall i \\
& y_{i j^{\prime}}=\left\{\begin{array}{l}
1, \text { if } x_{i j^{\prime}} C_{i j^{\prime}}\left(Q_{i j^{\prime}}\right)+\sqrt{2 K_{i} H_{i} x_{i j^{\prime}}} \leq \\
0, \text { otherwise } x_{i j} C_{i j}\left(Q_{i j}\right)+1 / 2 H_{i} Q_{i j}+K_{i} x_{i} / Q_{i j}, \forall i, j \neq j^{\prime} \\
x_{i}=\sum_{j=1, j \neq j^{\prime}}^{n} x_{i j}+x_{i j^{\prime}}, x_{i} \geq 0, \forall i, j \neq j^{\prime} \\
\sum_{i j^{\prime}}^{n} y_{i j^{\prime}} M_{i}, \forall i, j^{\prime}=1, \ldots, n \\
x_{i j} \leq y_{i j} M_{i}, \forall i, j \neq y_{i j^{\prime}}=1, y_{i j}, y_{i j^{\prime}} \in\{0,1\}, \forall i
\end{array}\right.
\end{aligned}
$$

where $x_{i}$ is decision variables, representing the different materials need to be purchased totally; $x_{i j}$ means the purchased quantity in segment $j$ for material $i ; y_{i j}$ and $y_{i j}$ is binary variables, denoting which unit price should be adopted for material $i$; $C_{i j}$ is a piecewise function about $Q_{i j}$, indicating the unit price with $Q_{i j}$ being purchase batch for material $i ; K_{i}$ and $H_{i}$ are setup cost for purchasing one batch and the holding cost per unit per unit of time held in inventory, respectively; $M_{i}$ is the upper bound for material $i$ can be supplied.

Equation (6a) shows the total cost for all materials to be minimized under many purchase schemes, where the first part means that the purchase batch of the scheme is economic purchase batch and the second part represents that the purchase batch in the scheme is the different demarcation point. Each of the schemes is combined with supply cost, setup cost and holding cost. Equation (6b) guarantees the constraints for 
different materials supplied/produced/consumed. Equation (6c) denotes the unit price is a piecewise function, which is decided according to the purchase batch. Equation (6d) shows the purchase batch resulted from Equation (3). In Equation (6e), binary variables are used to identify which unit price should be undertaken for different materials while Equation (6f) guarantees only one unit can be adopted for each material. Equations $(6 \mathrm{~g})$ and $(6 \mathrm{~h})$ are used to guarantee the materials less than the maximum supply. Equation (6i) means that the actual purchased material $i$ is the sum of purchased quantity in all segments and the non-negativity of the corresponding decision variables.

The developed INP model can effectively deal with quantity discount problem in supply systems under deterministic situation. However, it is incapable of tackling uncertainties in the objective function and in the left- and right-hand sides of constraints presented as interval values. In fact, most cost parameters cannot be determined easily because they often change in some ranges followed with the market fluctuation. For example, unit prices for purchase material may increase with the resources shortage and decrease with resources oversupply, which can fluctuate in a certain range. Therefore, interval-parameter programming (IPP) technique can be introduced into the proposed INP model to deal with interval values, leading to an inexact inventory nonlinear programming (IINP) model as follows:

Min

$$
\begin{aligned}
f^{ \pm}= & \sum_{i=1}^{m}\left(x_{i j}^{ \pm} C_{i j^{\prime}}^{ \pm}\left(Q_{i j^{ \pm}}^{ \pm}\right)+\sqrt{2 K_{i}^{ \pm} H_{i}^{ \pm} X_{i j^{ \pm}}^{ \pm}}\right)+\sum_{i=1}^{m} \sum_{j=1, j \neq j^{\prime}}^{n}\left(x_{i j}^{ \pm} C_{i j}^{ \pm}\left(Q_{i j}^{ \pm}\right)\right. \\
& \left.+1 / 2 H_{i}^{ \pm} Q_{i j}^{ \pm} y_{i j}^{ \pm}+K_{i}^{ \pm} x_{i j}^{ \pm} / Q_{i j}^{ \pm}\right)
\end{aligned}
$$

subject to:

$\sum_{i=1}^{m} a_{i l}^{ \pm} x_{i}^{ \pm} \geq b_{l}^{ \pm}, l=1,2, \ldots, r$

$C_{i j^{\prime}}^{ \pm}\left(Q_{i j^{\prime}}^{ \pm}\right)=C_{i j^{\prime}}^{ \pm}, C_{i j-1}^{ \pm}\left(Q_{i j-1}^{ \pm}\right)>C_{i j^{\prime}}^{ \pm}\left(Q_{i j^{\prime}}^{ \pm}\right)>C_{i j}^{ \pm}\left(Q_{i j}^{ \pm}\right)$,

if $Q_{i j-1}^{ \pm} \leq Q_{i j}^{ \pm}<Q_{i j}^{ \pm}, \forall i, j \neq j^{\prime}$

$Q_{i j^{\prime}}^{ \pm}=\sqrt{2 K_{i}^{ \pm} X_{i j}^{ \pm} / H_{i}^{ \pm}}, \forall i$

$y_{i j^{\prime}}^{ \pm}=\left\{\begin{array}{l}1, \text { if } x_{i j}^{ \pm} C_{i j^{\prime}}^{ \pm}\left(Q_{i j}^{ \pm}\right)+\sqrt{2 K_{i}^{ \pm} H_{i}^{ \pm} x_{i j^{\prime}}^{ \pm}} \\ \leq \min x_{i j}^{ \pm} C_{i j}^{ \pm}\left(Q_{i j}^{ \pm}\right)+1 / 2 H_{i}^{ \pm} Q_{i j}^{ \pm}+K_{i} x_{i j}^{ \pm} / Q_{i j}^{ \pm}, \forall i, j \neq j^{\prime}(7 \mathrm{e}) \\ 0, \text { otherwise }\end{array}\right.$

$\sum_{j=1, j \neq j^{\prime}}^{n} y_{i j}^{ \pm}+y_{i j^{\prime}}^{ \pm}=1, y_{i j}^{ \pm}, y_{i j^{\prime}}^{ \pm} \in\{0,1\}, \forall i$

$$
\begin{aligned}
& x_{i j}^{ \pm} \leq y_{i j}^{ \pm} M_{i}^{ \pm}, \forall i, j \neq j^{\prime} \\
& x_{i j^{\prime}}^{ \pm} \leq y_{i j^{\prime}}^{ \pm} M_{i}^{ \pm}, \forall i, j^{\prime}=1, \ldots, n \\
& x_{i}^{ \pm}=\sum_{j=1, j \neq j^{\prime}}^{n} x_{i j}^{ \pm}+x_{i j^{\prime}}^{ \pm}, x_{i}^{ \pm} \geq 0, \forall i, j \neq j^{\prime}
\end{aligned}
$$

where $x_{i}^{ \pm}, y_{i j}^{ \pm}, C_{i j}^{ \pm}, K_{i}^{ \pm}, H_{i}^{ \pm}, b_{l}^{ \pm}, Q_{i j}^{ \pm}, M_{i}^{ \pm}$are interval parameters/variables, and the '-' and ' + ' superscripts represent the lower and upper bounds of an interval parameter/variable, respectively (Huang and Cao, 2011).

\subsection{Solution Method}

Because there is nonlinearity in the objective function of IINP model, it is difficult to identify the uncertain relationships between the objective function and the related decision variables when using the interactive algorithm to solve model (7) for the intervals (Li et al., 2009). Consequently, a $0 \sim 1$ piecewise linearization approach is offered to handle such difficulties. A number of binary variables will be introduced as the decision variables to identify which segment is mostly approximate the nonlinear objective function. Thus, model (7) could be converted into as follows:

$$
\begin{aligned}
\operatorname{Min} & f^{ \pm}=\sum_{i=1}^{m} \sum_{k=1}^{s}\left(x_{i j k}^{ \pm} C_{i j}^{ \pm}\left(Q_{i j}^{ \pm}\right)+\alpha_{i k}^{ \pm} X_{i j k}^{ \pm}+\beta_{i k}^{ \pm} Z_{i k}^{ \pm}\right)+ \\
& \sum_{i=1}^{m} \sum_{j=1, j \neq j}^{n}\left(x_{i j}^{ \pm} C_{i j}^{ \pm}\left(Q_{i j}^{ \pm}\right)+1 / 2 H_{i}^{ \pm} Q_{i j}^{ \pm} y_{i j}^{ \pm}+K_{i}^{ \pm} X_{i j}^{ \pm} / Q_{i j}^{ \pm}\right)
\end{aligned}
$$

subject to:

$$
\begin{aligned}
& \sum_{i=1}^{m} a_{i l}^{ \pm} x_{i}^{ \pm} \geq b_{l}^{ \pm}, l=1,2, \ldots, r \\
& C_{i j}^{ \pm}\left(Q_{i j}^{ \pm}\right)=C_{i j^{\prime}}^{ \pm}, C_{i j-1}^{ \pm}\left(Q_{i j-1}^{ \pm}\right)>C_{i j^{\prime}}^{ \pm}\left(Q_{i j^{\prime}}^{ \pm}\right)>C_{i j}^{ \pm}\left(Q_{i j}^{ \pm}\right), \\
& \text {if } Q_{i j-1}^{ \pm} \leq Q_{i j^{\prime}}^{ \pm}<Q_{i j}^{ \pm}, \forall i, j \neq j \\
& Q_{i j^{\prime}}^{ \pm}=\sqrt{2 K_{i}^{ \pm} X_{i j^{\prime}}^{ \pm} / H_{i}^{ \pm}}, \forall i
\end{aligned}
$$

$y_{i j^{\prime}}^{ \pm}=\left\{\begin{array}{l}1, \text { if } x_{i j k}^{ \pm} C_{i j^{\prime}}^{ \pm}\left(Q_{i j^{\prime}}^{ \pm}\right)+\alpha_{i k}^{ \pm} X_{i j^{\prime} k}^{ \pm}+\beta_{i k}^{ \pm} z_{i k}^{ \pm} \leq \\ \min x_{i j}^{ \pm} C_{i j}^{ \pm}\left(Q_{i j}^{ \pm}\right)+1 / 2 H_{i}^{ \pm} Q_{i j}^{ \pm}+K_{i} x_{i j}^{ \pm} / Q_{i j}^{ \pm}, \forall i, j \neq j \\ 0, \text { otherwise }\end{array}\right.$

$\sum_{j=1, j \neq j^{\prime}}^{n} y_{i j}^{ \pm}+y_{i j^{\prime}}^{ \pm}=1, y_{i j}^{ \pm}, y_{i j^{\prime}}^{ \pm} \in\{0,1\}, \forall i$ 


$$
\begin{aligned}
& x_{i j}^{ \pm} \leq y_{i j}^{ \pm} M_{i}^{ \pm}, \forall i, j \neq j \\
& x_{i j^{\prime} k}^{ \pm} \leq y_{i j^{ \pm}}^{ \pm} M_{i}^{ \pm}, \forall i, j^{\prime}=1, \ldots, n \\
& z_{i k}^{ \pm}=\left\{\begin{array}{l}
1, \text { if } \underline{R}_{i k} \leq x_{i j^{\prime} k}^{ \pm} \leq \bar{R}_{i k}, \forall i, \mathrm{k} \\
0, \text { otherwise }
\end{array}\right. \\
& x_{i j^{\prime} k}^{ \pm}-\underline{R}_{i k} z_{i k}^{ \pm} \geq 0, \forall i, k \\
& x_{i j^{\prime} k}^{ \pm}-\bar{R}_{i k} z_{i k}^{ \pm} \leq 0, \forall i, k \\
& \sum_{k=1}^{s} z_{i k}^{ \pm}=1, \forall i \\
& x_{i}^{ \pm}=\sum_{j=1, j \neq j^{\prime}}^{n} x_{i j}^{ \pm}+\sum_{k=1}^{s} x_{i j^{\prime} k}^{ \pm}, x_{i}^{ \pm} \geq 0, \forall i, j \neq j
\end{aligned}
$$

where $z_{i k}^{ \pm}$is binary variable for determining which segment of $x_{i j k}^{ \pm} ; k$ indicates segment of decision variables; $\alpha_{i k}^{ \pm}$denotes the slope of setup and holding costs curve in segment $k ; \beta_{i k}^{ \pm}$is the $Y$-intercept of setup cost and holding costs curve in segment $k$; $\underline{R}_{i k}$ and $\bar{R}_{i k}$ mean the lower and upper bounds of segment $k$, respectively. Obviously, model (8) is a conventional intervalparameter mixed integer linear program (IMILP), which can be transformed into two deterministic submodels that correspond to the lower- and upper-bound of the objective function value, based on interactive algorithm (Fan and Huang, 2012). The two submodels corresponding to $f^{-}$and $f^{+}$can be formulated as follows:

\section{Lower-bound submodel}

$\operatorname{Min} f^{-}=$

$\sum_{i=1}^{m} \sum_{k=1}^{s}\left(x_{i j^{\prime} k}^{-} C_{i j}^{-}\left(Q_{i j^{\prime}}^{-}\right)+\left|\alpha_{i k}\right|^{-} \operatorname{Sign}\left(\alpha_{i k}^{-}\right) x_{i j k}^{-}+\left|\beta_{i k}\right|^{-} \operatorname{Sign}\left(\beta_{i k}^{-}\right) z_{i k}^{-}\right)$

$+\sum_{i=1}^{m} \sum_{j=1, j \neq j^{\prime}}^{n}\left(x_{i j}^{-} C_{i j}^{-}\left(Q_{i j}^{-}\right)+1 / 2 H_{i}^{-} Q_{i j}^{-} y_{i j}^{-}+K_{i}^{-} x_{i j}^{-} / Q_{i j}^{-}\right)$

subject to:

$\sum_{i=1}^{m}\left|a_{i l}\right|^{+} \operatorname{Sing}\left(a_{i l}^{+}\right) x_{i}^{-} \geq b_{l}^{-}, l=1,2, \ldots, r$

$C_{i j^{\prime}}^{-}\left(Q_{i j^{\prime}}^{-}\right)=C_{i j^{\prime}}^{-}, C_{i j-1}^{-}\left(Q_{i j-1}^{-}\right)>C_{i j^{\prime}}^{-}\left(Q_{i j^{\prime}}^{-}\right)>C_{i j}^{-}\left(Q_{i j}^{-}\right)$,

if $Q_{i j-1}^{-} \leq Q_{i j}^{-}<Q_{i j}^{-}, \forall i, j \neq j^{\prime}$

$$
\begin{aligned}
& Q_{i j^{\prime}}^{-}=\sqrt{2 K_{i}^{-} x_{i j^{\prime}}^{-} / H_{i}^{-}}, \forall i \\
& y_{i j^{\prime}}^{-}=\left\{\begin{array}{l}
1, \text { if } x_{i j^{\prime} k}^{-} C_{i j^{\prime}}^{-}\left(Q_{i j^{\prime}}^{-}\right)+\left|\alpha_{i k}\right|^{-} \operatorname{Sign}\left(\alpha_{i k}^{-}\right) x_{i j k}^{-} \\
+\left|\beta_{i k}\right|^{-} \operatorname{Sign}\left(\beta_{i k}^{-}\right) z_{i k}^{-} \leq \min x_{i j}^{-} C_{i j}^{-}\left(Q_{i j}^{-}\right), \forall i, j \neq j \\
+1 / 2 H_{i}^{-} Q_{i j}^{-}+K_{i}^{-} x_{i j}^{-} / Q_{i j}^{-} \\
0, \text { otherwise }
\end{array}\right.
\end{aligned}
$$

$$
\sum_{j=1, j \neq j^{\prime}}^{n} y_{i j}^{-}+y_{i j^{\prime}}^{-}=1, y_{i j}^{-}, y_{i j^{\prime}}^{-} \in\{0,1\}, \forall i
$$

$x_{i j}^{-} \leq y_{i j}^{-} M_{i}^{-}, \forall i, j \neq j^{\prime}$

$x_{i j^{\prime} k}^{-} \leq y_{i j^{\prime}}^{-} M_{i}^{-}, \forall i, j^{\prime}=1, \ldots, n$

$Z_{i k}^{-}=\left\{\begin{array}{l}1, \text { if } \underline{R}_{i k} \leq X_{i j k}^{-} \leq \bar{R}_{i k} \\ 0, \text { otherwise }\end{array}, \forall i, k\right.$

$x_{i j^{\prime} k}^{-}-\underline{R}_{k} z_{i k}^{-} \geq 0, \forall i, k$

$x_{i j k}^{-}-\bar{R}_{k} z_{i k}^{-} \leq 0, \forall i, k$

$\sum_{k=1}^{s} z_{i k}^{-}=1, \forall i$

$x_{i}^{-}=\sum_{j=1, j \neq j^{\prime}}^{n} x_{i j}^{-}+\sum_{k=1}^{s} x_{i j j^{\prime}}^{-}, x_{i}^{-} \geq 0, \forall i, j \neq j^{\prime}$

\section{Upper-bound submodel}

$$
\begin{aligned}
& \operatorname{Min} f^{+}= \\
& \sum_{i=1}^{m} \sum_{k=1}^{s}\left(x_{i j^{+} k}^{+} C_{i j^{\prime}}^{+}\left(Q_{i j^{+}}^{+}\right)+\left|\alpha_{i k}\right|^{+} \operatorname{Sign}\left(\alpha_{i k}^{+}\right) x_{i j^{\prime} k}^{+}+\left|\beta_{i k}\right|^{+} \operatorname{Sign}\left(\beta_{i k}^{+}\right) z_{i k}^{+}\right) \\
& +\sum_{i=1}^{m} \sum_{j=1, j \neq j^{\prime}}^{n}\left(x_{i j}^{+} C_{i j}^{+}\left(Q_{i j}^{+}\right)+1 / 2 H_{i}^{+} Q_{i j}^{+} y_{i j}^{+}+K_{i}^{+} x_{i j}^{+} / Q_{i j}^{+}\right)
\end{aligned}
$$

subject to:

$$
\begin{aligned}
& \sum_{i=1}^{m}\left|a_{i l}\right|^{-} \operatorname{Sing}\left(a_{i l}^{-}\right) x_{i}^{+} \geq b_{l}^{+}, l=1,2, \ldots, r \\
& C_{i j^{\prime}}^{+}\left(Q_{i j^{\prime}}^{+}\right)=C_{i j^{\prime}}^{+}, C_{i j-1}^{+}\left(Q_{i j-1}^{+}\right)>C_{i j^{\prime}}^{+}\left(Q_{i j^{\prime}}^{+}\right)>C_{i j}^{+}\left(Q_{i j}^{+}\right), \\
& \text {if } Q_{i j-1}^{+} \leq Q_{i j^{\prime}}^{+}<Q_{i j}^{+}, \forall i, j \neq j^{\prime}
\end{aligned}
$$


$Q_{i j}^{+}=\sqrt{2 K_{i}^{+} X_{i j}^{+} / H_{i}^{+}}, \forall i$

$y_{i j^{\prime}}^{+}=\left\{\begin{array}{l}1, \text { if } x_{i j k}^{+} C_{i j^{\prime}}^{+}\left(Q_{i j^{+}}^{+}\right)+\left|\alpha_{i k}\right|^{+} \operatorname{Sign}\left(\alpha_{i k}^{+}\right) x_{i j k}^{+} \\ +\left|\beta_{i k}\right|^{+} \operatorname{Sign}\left(\beta_{i k}^{+}\right) z_{i k}^{+} \leq \min x_{i j}^{+} C_{i j}^{+}\left(Q_{i j}^{+}\right), \forall i, j \neq j \\ +1 / 2 H_{i}^{+} Q_{i j}^{+}+K_{i}^{+} x_{i j}^{+} / Q_{i j}^{+} \\ 0, \text { otherwise }\end{array}\right.$

$\sum_{j=1, j \neq j^{\prime}}^{n} y_{i j}^{+}+y_{i j^{\prime}}^{+}=1, y_{i j}^{-}, y_{i j^{\prime}}^{-} \in\{0,1\}, \forall i$

$x_{i j}^{+} \leq y_{i j}^{+} M_{i}^{+}, \forall i, j \neq j^{\prime}$

$x_{i j^{\prime} k}^{+} \leq y_{i j}^{+} M_{i}^{+}, \forall i, j^{\prime}=1, \ldots, n$

$Z_{i k}^{+}=\left\{\begin{array}{l}1, \text { if } \underline{R}_{i k} \leq X_{i j k}^{+} \leq \bar{R}_{i k} \\ 0, \text { otherwise }\end{array}, \forall i, k\right.$

$x_{i j k}^{+}-\underline{R}_{k} z_{i k}^{+} \geq 0, \forall i, k$

$X_{i j^{\prime} k}^{+}-\bar{R}_{k} z_{i k}^{+} \leq 0, \forall i, k$

$\sum_{k=1}^{s} z_{i k}^{+}=1, \forall i$

$x_{i}^{+}=\sum_{j=1, j \neq j^{\prime}}^{n} x_{i j}^{+}+\sum_{k=1}^{s} x_{i j^{\prime} k}^{+}, x_{i j}^{+} \geq x_{i j o p t}^{-}, x_{i j k}^{+} \geq x_{i j k o p t}^{-}, \forall i, j \neq j^{\prime}$

$y_{i j}^{+} \geq y_{i j o p t}^{-}, \forall i, j$

$z_{i k}^{+} \geq z_{i k o p t}^{-}, \forall i, k$

where the values of $x_{i j o p t}^{-}, x_{i j k \text { opt }}^{-}, y_{i j \text { opt }}^{-}, z_{i k \text { opt }}^{-}$and $Q_{i j \text { opt }}^{-}$are solved by submodel (9). Let $x_{i j o p t}^{+}, x_{i j k \text { opt }}^{+}, y_{i j \text { opt }}^{+}, z_{i k \text { opt }}^{+}$and $Q_{i j \text { opt }}^{+}$be solutions of submodel (10). When IINP model [i.e., model (7)] is linearized through $0 \sim 1$ piecewise approxima-

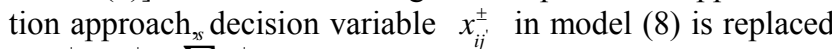
by $x_{i j k}^{ \pm}\left(x_{i j}^{ \pm}=\sum x_{i j k}^{ \pm}\right.$and $\left.i=1, \ldots, m\right)$. Therefore, the solutions of model (8) kean then be obtained through integration of the solutions from submodels (9) and (10), which can be presented as follows:

$$
\begin{aligned}
& x_{i \text { opt }}^{ \pm}=\left[\sum_{j=1, j \neq j^{\prime}}^{n} X_{i j \text { opt }}^{-}+\sum_{k=1}^{s} X_{i j j^{-} \text {opt }}^{-}, \sum_{j=1, j \neq j^{\prime}}^{n} X_{i j \text { opt }}^{+}+\sum_{k=1}^{s} X_{i j j^{\prime} \text { opt }}^{+}\right], \\
& \forall i, j \neq j \\
& y_{i j o p t}^{ \pm}=\left[y_{i j o p t}^{-}, y_{i j o p t}^{+}\right] \\
& Z_{i \mathrm{kopt}}^{ \pm}=\left[Z_{i \mathrm{k} \text { opt }}^{-}, Z_{i \mathrm{kopt}}^{+}\right] \\
& f_{i \text { opt }}^{ \pm}=\left[f_{i \text { opt }}^{-}, f_{i o p t}^{+}\right] \\
& Q_{i j \text { opt }}^{ \pm}=\left[Q_{i j \text { opt }}^{-}, Q_{i j \text { opt }}^{+}\right]
\end{aligned}
$$

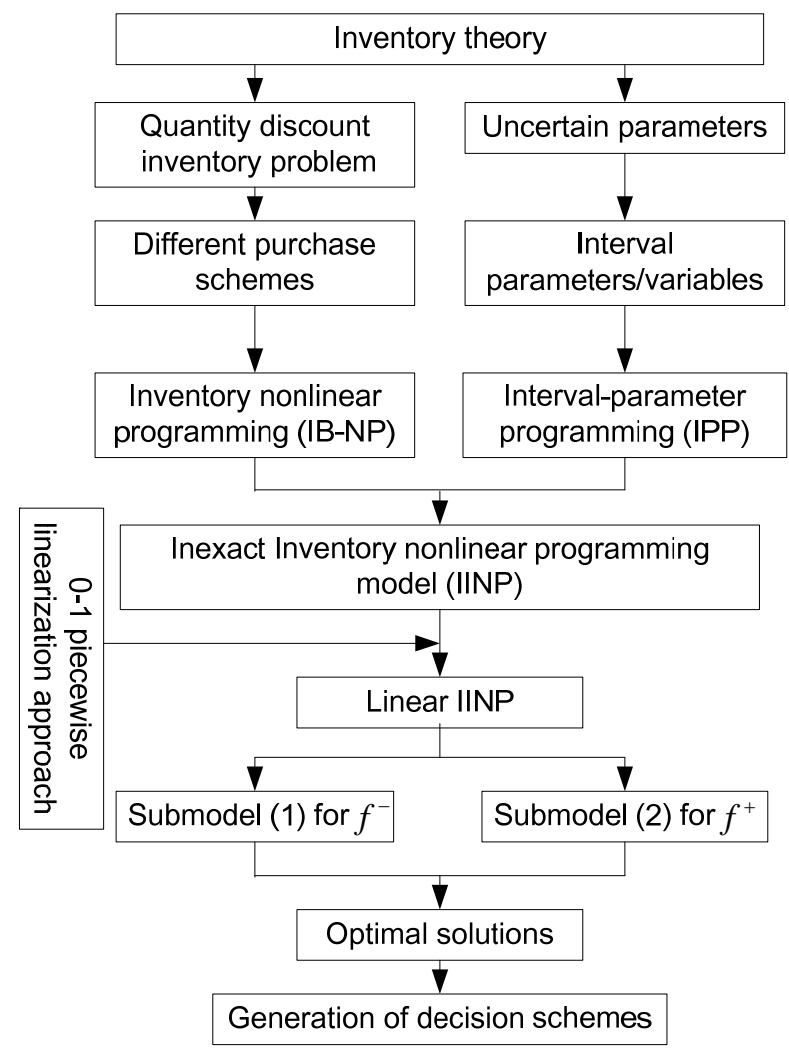

Figure 1. Flow diagram of the IINP model.

Figure 1 depicts the framework of the IINP model with the objective function being minimized. The IINP model can not only deal with uncertainty expressed in forms of intervals but also obtain the global solutions with nonlinear objective function. Moreover, it can effectively reflect the quantity discount problem based on the introduction of binary variables. Therefore, the IINP model can be used for discount inventory problems to obtain the best purchase batch associated with different unit prices under uncertainty. 


\section{Application}

The City of WuAn is located in the southern Hebei province. The city occupies an administrative area of around 1,806 $\mathrm{km}^{2}$, and makes up of 22 townships and 502 administrative villages, with 680 thousand permanent populations. Based on Statistics Bureau of Hebei, its GDP reached to 52.83 billion RMB in 2011(Hebei Statistics Bureau, 2011). It has abundant mining resources, such as coal, iron, and marble. With the economic development and population growth, its amount of electricity demand has a rapid growth in recent years. Based on Statistics Bureau of WuAn, its electricity consumption increased from 280 PJ in 2005 to 390 PJ in 2010(WuAn Statistics Bureau, 2011). If the electricity generation cannot satisfy the end-users' demands, the local decision makers have to invest more funds to expand the capacities of the current power-generation facilities to meet the city's electricity selfsupply.

Energy resources supply in the city mainly relies on coal and natural gas, which can be from import and mining sources. Resources import from other regions usually has higher costs, which can be limited by the availability of electricity from adjacent power grids and different purchase schemes. In detail, resources import is usually in a large quantity, which may refer to different batch prices and thus lead to various purchase options. In real-world practical problems, the unit prices for different energy resources are varied with the purchase batches; this means that the more the purchase batch, the lower the unit price is, and vice versa. Moreover, importing too much energy resources can increase the holding cost (the cost for inventory management) and bring burden to the storage capacity, even lead to huge quantity of tied-up funds; importing too little energy resources cannot meet the energy demand with higher unit price, and also increase the purchase frequency, leading to an increased setup cost (the cost for purchasing one batch in order to replenish the stock, including the handling charge, communication expenses, travelling expenses occurred in the purchasing process). Due to the limitation of resources development planning from country, the city's energy resources supply partly depends on resources import from the other regions such as $\mathrm{Ci}$ county and Shanxi province.

Although coal is quite dirty, it accounts for an important part in WuAn's energy resources supply. The amount of coal imported from other regions takes up to $45 \%$ of the total amount of coal consumption in this city. Most of the coal production is used for steel production and electricity generation, while the rest is exported. In addition, the electricity generation is far from meeting its increasing demand. According to its future economic development planning and the relationship between economic development and electricity demand, the electricity demand within a 15-year planning horizon (from 2016 to 2030 with three 5-year periods) for this city can be calculated; the electricity demands will be [550, 690], [600, 820], [700, 930] PJ in the three periods (He et al., 2009). The city's existing electricity capacities are only $1.97 \mathrm{GW}$, including $0.28 \mathrm{GW}$ of natural gas-fired generation, $1.4 \mathrm{GW}$ of coal-fired generation, $0.26 \mathrm{GW}$ of hydropower generation,
$0.014 \mathrm{GW}$ of solar power generation, and $0.016 \mathrm{GW}$ of methane power generation. Wherein, the electricity generation from solar power and methane power accounts for $1.5 \%$ of the total electricity generation, which are mostly for residential living usage in villages. Because solar power and methane power are limited by specific conditions and techniques and unstable, they are not considered in this study.

Energy production and consumption, waste disposal and industrial processes are the primary sources of pollution emissions in this city. For instance, coal-fired power plant is the largest source of sulfur dioxide $\left(\mathrm{SO}_{2}\right)$, nitrogen oxides $\left(\mathrm{NO}_{\mathrm{x}}\right)$ and particulate matter (PM) emissions, while natural gas-fired power plant is the second largest source of $\mathrm{SO}_{2}$ and $\mathrm{NO}_{\mathrm{x}}$ emissions. The amount of $\mathrm{SO}_{2}$ emission reached $48.41 \times 10^{3}$ tonne in 2008 , which accounts for $47 \%$ of the total emission of $\mathrm{SO}_{2}$ in this city. The amounts of $\mathrm{NO}_{\mathrm{x}}$ and $\mathrm{PM}$ emissions reached $50.13 \times 10^{3}$ and $12.60 \times 10^{3}$ tonne in 2008 , respectively. In order to improve air quality, WuAn has made significant achievement by adoption of many energy policies and air quality control measures. By the end of 2010, the total emission amounts of major pollutants had been dropped $20 \%$ compared with 2005. In the future, the government would pay more attention to cut the total emission of major pollutants to realize the objective of "Green City". Therefore, it is necessary to identify the uncertain and complex responses of various energy resources supply schemes and electricity generation strategies to emission-mitigation measures, and an electric power-environment system optimization planning is desired by local decision makers.

The city's electric power systems have complex interacttion with a number of subsystems. Figure 2 presents interacttive relationships between different system sectors, containing energy resources supply, transportation, inventory, resources conversion and utilization. Electricity utilization of this city includes agriculture, commerce, industry, residents, and municipal sectors. The city's pillar industries contain metallurgy industries and building materials industries. In 2008, the electricity consumption of pillar industries accounted for $80 \%$ of the total electricity consumption, which control the city's economic lifeblood. The municipal sectors consist of water supply, power supply, heat supply, gas supply and others. Generally, electric power activities/services have relationships with relevant infrastructural investments and pollutant emissions, and have influences on local ecosystems. However, institutional measures and socio-economic activities would also have impacts on the electric power systems through different policies, actions and strategies, which could then have indirect effects on the other factors within the community. Correspondingly, electric power systems planning will help to design a series of activities under these limited "allowances" for energy resources supply and allocation, in order to achieve desired socioeconomic and environmental targets.

In this study, an electric power generation system in one small city of China is studied. Since electric power system planning includes electricity generation which may refer to energy resources (e.g., coal) purchase, transportation, storage and usage, it is noted that energy resources purchase process 


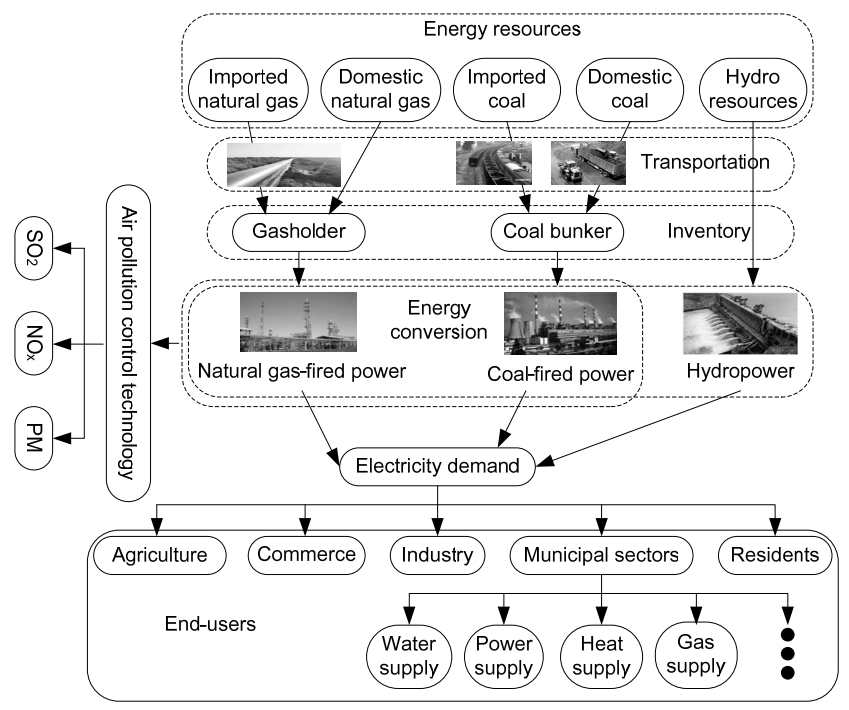

Figure 2. Flow diagram of the energy supply- electricity demand system.

is a business process, which would refer to resources unit prices, purchase batches and purchase time periods. Furthermore, due to limited capital and production continuity in electric power systems, it is necessary to optimize the resources purchase scheme to save investments on material purchase and storage. The aim of inventory theory is to determine rules that managers can use to minimize the cost (or maximize the benefit) associated with maintaining inventory and meeting users' demand. In addition, as for the material supply problem with diverse unit prices, a quantity discount inventory model is helpful to answer the following questions: what material should be purchased; where material should be purchased from, local and/or other regions; which scheme/unit price should be selected; when and how much material should be purchased. Therefore, introducing the inventory theory into electric power systems would be helpful to solve these problems in this study case.

In addition, there are many other complex processes in electric power systems that should be considered by the local decision makers, such as energy resources transportation, resources conversion and utilization as well as the resulting pollutant emissions. Furthermore, uncertain parameters, purchase schemes, and expansion options should be analyzed by suitable system analysis techniques. For example, several factors may affect the system cost, purchase cost, transportation cost, operation cost and the emission loads of air pollutants in real-world problems. The system cost may change along with the resources quality, the prices of resources, the economic development levels and the environmental planning policy; the purchase cost may vary with the market fluctuation and purchase quantity; the transportation cost are affected by the distances and different transportation tools; the emission loads are influenced by varied resources, the utilization conditions and the amount of electricity generation. In electric power systems, the related costs and technologic parameters could be stated as intervals. These parameters are described with their lower- and upper- bounds to effectively reflect the real problems. The determination of which purchase options for energy resources supply should be selected and whether or not capacity expansion should be adopted can be identified by binary variables. To handle such complexities and uncertainties, systematical electric power systems planning is expected under comprehensive study and application. In the study area, multiple energy resources supply schemes need to be determined with availabilities for satisfying the electricity generation. This leads to an application of inexact inventory nonlinear programming (IINP) to electric power systems planning. If local energy resources supply cannot adequately meet the electricity generation, decision makers will need to pay higher unit prices to import resources from other regions. In this case, the unit prices for different energy resources may be varied with the purchase batches, which means that the more the purchase batch, the lower the unit price is, and vice versa. No matter which unit price would be selected in response to the shortages of energy resources, bad influence would be happened. Furthermore, if electricity supply cannot sufficiently satisfy the end-users' demands, decision makers will need to invest more funds to expand the capacities of the current facilities. The problem under consideration is how to reasonably determine energy resources supply schemes and decide how to expansion to minimize the net system costs. Decision makers need to ascertain the desired energy resources supply scheme, facility-expansion and air pollutants mitigation strategy with a minimized system cost.

Generally, the problems existing in electric power systems should be considered: (a) how to efficiently select an optimized purchase scheme with different unit prices, purchase batches and sound timing consideration, (b) how to effectively determine optimized capacity expansion scheme under different electricity demand level, and (c) how to integrate energy resources and environmental policies into the study problem with minimum system cost and risk. According to the proposed IINP method, the study problem can be formulated as follows:

Min $f^{ \pm}=(1)+(2)+(3)+(4)+(5)$

(1) Cost for purchasing resources

$$
\begin{aligned}
& \sum_{t=1}^{3} \sum_{i=1}^{4}\left(X S_{i t, q=1}^{ \pm} C_{i t, q=1}^{ \pm}+\sqrt{2 K C_{i t}^{ \pm} H C_{i t}^{ \pm} X S_{i t, q=1}^{ \pm}}\right)+ \\
& \sum_{t=1}^{3} \sum_{i=1}^{4}\left(X S_{i t, q=2}^{ \pm} C_{i t, q=2}^{ \pm}+1 / 2 H C_{i t}^{ \pm} Q_{i t}^{ \pm \pm} Y_{i t, q=2}^{ \pm}+K C_{i t}^{ \pm} X S_{i t, q=2}^{ \pm} / Q_{i t}^{ \pm}\right)
\end{aligned}
$$

(2) Cost for transporting resources

$\sum_{t=1}^{3} \sum_{i=1}^{4} X S_{i t}^{ \pm} T C_{i t}^{ \pm}$ 
(3) Cost for capacity expansion

$\sum_{t=1}^{3} \sum_{j=1}^{3}\left(F C_{j t}^{ \pm} Z_{j t}^{ \pm}+V C_{j t}^{ \pm} X E_{j t}^{ \pm}\right)$

(4) Operation cost for electricity generation

$$
\begin{aligned}
& \sum_{j=1}^{2} \sum_{t=1}^{3}\left(R E S_{j t}^{ \pm}+\sum_{t=1}^{t} X E_{j t}^{ \pm}\right) C P T_{j t}^{ \pm} E C P_{j t}^{ \pm} O C_{j t}^{ \pm}+ \\
& \sum_{t=1}^{3}\left(R E S_{j=3, t}^{ \pm}+\sum_{t=1}^{t} X E_{j=3, t}^{ \pm}\right) C P T_{j=3, t}^{ \pm} O C_{j=3, t}^{ \pm}
\end{aligned}
$$

(5) Operation cost for controlling pollution emissions

$\sum_{t=1}^{3} \sum_{j=1}^{2} \sum_{m_{n}=1}^{2} A N O_{j m_{n} t}^{ \pm} O C N_{m_{n} t}^{ \pm}+\sum_{t=1}^{3} \sum_{j=1}^{2} \sum_{m_{p}=1}^{3} A P M_{j m_{p} t}^{ \pm} O C P_{m_{p} t}^{ \pm}$

$+\sum_{t=1}^{3} \sum_{j=1}^{2} \sum_{m_{s}=1}^{3} A S O_{j m_{s} t}^{ \pm} O C S_{m_{s} t}^{ \pm}$

subject to:

[Constraints for natural gas mass balance]

$S E_{1 t}^{ \pm}=\sum_{i=1}^{2} X S_{i t}^{ \pm}-\sum_{j=1}\left(R E S_{j t}^{ \pm}+\sum_{t=1}^{t} X E_{j t}^{ \pm}\right) C P T_{j t}^{ \pm} E C P_{j t}^{ \pm}+S E_{1 t-1}^{ \pm} \geq 0$,

$t=1,2,3$

[Constraints for coal mass balance]

$S E_{2 t}^{ \pm}=\sum_{i=3}^{4} X S_{i t}^{ \pm}-\sum_{j=2}\left(R E S_{j t}^{ \pm}+\sum_{t=1}^{t} X E_{j t}^{ \pm}\right) C P T_{j t}^{ \pm} E C P_{j t}^{ \pm}+S E_{2 t-1}^{ \pm} \geq 0$,

$t=1,2,3$

[Constraints for hydropower mass balance]

$S E_{3 t}^{ \pm}=X S_{5 t}^{ \pm}-\left(R E S_{3 t}^{ \pm}+\sum_{t=1}^{t} X E_{3 t}^{ \pm}\right) C P T_{3 t}^{ \pm}+S E_{3 t-1}^{ \pm} \geq 0$,

$t=1,2,3$

[Constraints for electricity supply and demand balance]

$$
\begin{aligned}
& E_{t}^{ \pm}=\sum_{j=1}^{2}\left(R E S_{j t}^{ \pm}+\sum_{t=1}^{t} X E_{j t}^{ \pm}\right) C P T_{j t}^{ \pm} E C P_{j t}^{ \pm}+ \\
& \left(R E S_{3 t}^{ \pm}+\sum_{t=1}^{t} X E_{j t}^{ \pm}\right) C P T_{3 t}^{ \pm}+E_{t-1}^{ \pm}-D_{t}^{ \pm} \geq 0, t=1,2,3
\end{aligned}
$$

[Constraints for resources supply]
$X S_{i q t}^{ \pm} \leq Y_{i q t}^{ \pm} U X_{i t}^{ \pm}, \forall t, i=1,2,3,4, q=1,2$

$X S_{i t}^{ \pm} \leq U X_{i t}^{ \pm}, \forall t, i=5$

[Constraints for electricity peak load demand]

$$
\sum_{j=1}^{3}\left(R E S_{j}^{ \pm}+\sum_{t=1}^{t} X E_{j t}^{ \pm}\right) \geq P L_{t}, t=1,2,3
$$

[Constraints for capacity expansion of electricity-generation facilities]

$Z_{j t}^{ \pm}=\left\{\begin{array}{l}1, \text { if capacity expansion is undertaken } \\ 0, \text { if otherwise }\end{array}, \forall j, t\right.$

$0 \leq X E_{j t}^{ \pm} \leq U C E_{j t} Z_{j t}^{ \pm}, \forall j, t$

[Constraints for unit prices of imported energy resources]

$Y_{i 1 t}^{ \pm}=\left\{\begin{array}{l}1, \text { if } X S_{i t, q=1}^{ \pm} C_{i t, q=1}^{ \pm}+\sqrt{2 K C_{i t}^{ \pm} H C_{i t}^{ \pm} X S_{i t, q=1}^{ \pm}} \leq \\ \quad X S_{i t, q=2}^{ \pm} C_{i t, q=2}^{ \pm}+1 / 2 H C_{i t}^{ \pm} Q_{i t}^{ \pm}+K C_{i t}^{ \pm} X S_{i t, q=2}^{ \pm} / Q_{i t}^{ \pm}, \\ 0, \text { if otherwise }\end{array}\right.$

$\forall t, i=1,2,3,4$

$C_{i 1 t}^{ \pm}<C_{i 2 t}^{ \pm}$, if $Q_{i t}^{ \pm} \geq Q_{i t}^{ \pm}, Q_{i t}^{ \pm}=\sqrt{2 K C_{i t}^{ \pm} X S_{i t}^{ \pm} / H C_{i t}^{ \pm}} \geq 0, \forall t$,

$i=1,2,3,4$

$Y_{i 1 t}^{ \pm}+Y_{i 2 t}^{ \pm} \leq 1, \forall t, i=1,2,3,4$

[Constraints for air-pollution control demand]

$\sum_{m_{s}=1}^{3} A S O_{j m_{s} t}^{ \pm}=\left(R E S_{j t}^{ \pm}+\sum_{t=1}^{t} X E_{j t}^{ \pm}\right) C P T_{j t}^{ \pm} E C P_{j t}^{ \pm} S O E_{j t}^{ \pm}, \forall j, t$

$\sum_{m_{n}=1}^{2} A N O_{j m_{n} t}^{ \pm}=\left(R E S_{j t}^{ \pm}+\sum_{t=1}^{t} X E_{j t}^{ \pm}\right) C P T_{j t}^{ \pm} E C P_{j t}^{ \pm} N O E_{j t}^{ \pm}, \forall j, t$

$\sum_{m_{p}=1}^{3} A P M_{j m_{p} t}^{ \pm}=\left(R E S_{j t}^{ \pm}+\sum_{t=1}^{t} X E_{j t}^{ \pm}\right) C P T_{j t}^{ \pm} E C P_{j t}^{ \pm} P M E_{j t}^{ \pm}, \forall j, t$

[Constraints for air-pollution emissions] 


$$
\begin{aligned}
& \sum_{j=1}^{2} \sum_{m_{s}=1}^{3}\left(1-\eta_{m_{s} t}^{ \pm}\right) A S O_{j m_{s} t}^{ \pm} \leq E M S_{t}^{ \pm}, \forall t \\
& \sum_{j=1}^{2} \sum_{m_{n}=1}^{2}\left(1-\eta_{m_{n} t}^{ \pm}\right) A N O_{j m_{n} t}^{ \pm} \leq E M N_{t}^{ \pm}, \forall t \\
& \sum_{j=1}^{2} \sum_{m_{p}=1}^{3}\left(1-\eta_{m_{p} t}^{ \pm}\right) A P M_{j m_{p} t}^{ \pm} \leq E M P_{t}^{ \pm}, \forall t
\end{aligned}
$$

[Constraints for technology]

$$
X S_{i t}^{ \pm} \geq 0, \forall i, t
$$

$$
X S_{i t}^{ \pm}=\sum_{q=1}^{2} X S_{i q t}^{ \pm}, \forall t, i=1,2,3,4
$$

$$
E_{0}^{ \pm}=0 ; S E_{j 0}^{ \pm}=0, \forall j
$$

\section{Subscripts:}

$i=$ type of energy resources, $i=1,2,3,4,5 ; i=1$ for imported natural gas, $i=2$ for domestic natural gas, $i=3$ for imported coal, $i=4$ for domestic coal, $i=5$ for water

$j=$ type of power conversion technology, $j=1,2,3 ; j=1$ for natural gas-fired power, $j=2$ for coal-fired power, $j=3$ for hydropower

$q=$ type of unit price for energy resources, $q=1,2 ; q=1$ for higher unit price, $q=2$ for lower unit price

$m_{s}=$ type of $\mathrm{SO}_{2}$ control measure, $m_{\mathrm{s}}=1,2,3 ; m_{\mathrm{s}}=1$ for soda ash scrubber (SAS); $m_{s}=2$ for wet limestone scrubber (WLS), $m_{s}=3$ for lime spray dryer (LSD)

$m_{n}=$ type of $\mathrm{NO}_{\mathrm{x}}$ control measure, $m_{n}=1,2 ; m_{n}=1$ for selective catalytic reduction (SCR), $m_{n}=2$ for selective noncatalytic reduction (SNCR)

$m_{p}=$ type of particulate matter $(\mathrm{PM})$ control measure, $m_{p}=1$, 2, $3 ; m_{p}=1$ for fabric filiter/baghouse $(\mathrm{BH}), m_{p}=2$ for electrostatic precipitator (ESP), $m_{p}=3$ for wet collector (WC) $t=$ time period, $t=1,2,3$

\section{Parameters:}

$C_{i q t}^{ \pm}=$unit price for energy resources $(i=1,2,3,4 ; q=1,2)$ in period $t\left(10^{6} \mathrm{US} \$ / \mathrm{PJ}\right)$

$D_{t}=$ total electricity demand in period $t(\mathrm{PJ})$

$E_{t}^{ \pm}=$surplus electricity when the total electricity demand $D_{t}$ is satisfied in period $t(\mathrm{PJ})$

$Q_{i t}^{\prime \pm}=$ the demarcation point of the price discount for energy resource $i$ in period $t(\mathrm{PJ})$
$S E_{j t}^{ \pm}=$surplus electricity for power conversion technology $j$ in period $t(\mathrm{PJ})$

$F C_{j t}^{ \pm}=$fixed-charge cost for capacity expansion of power conversion technology $j$ in period $t\left(10^{6} \mathrm{US} \$\right)$

$H C_{i t}^{ \pm}=$holding cost per unit per unit of time held in inventory for energy resource $i$ in period $t\left(10^{6} \mathrm{US} \$ / \mathrm{a}\right)$

$K C_{i t}^{ \pm}=$setup cost for purchasing one batch of energy resource $i$ in period $t\left(10^{6} \mathrm{US} \$\right)$

$O C_{j t}^{ \pm}=$operation cost of power conversion technology $j$ for electricity generation in period $t\left(10^{6} \mathrm{US} \$ / \mathrm{PJ}\right)$

$P L_{t}=$ peak load demand in period $t(\mathrm{GW})$

$T C_{i t}^{ \pm}=$transportation cost per unit for energy resource $i$ in period $t\left(10^{6} \mathrm{US} \$ / \mathrm{PJ}\right)$

$U X_{i t}^{ \pm}=$upper bound for allowable energy resource $i$ supply in period $t(\mathrm{PJ})$

$V C_{j t}^{ \pm}=$variable cost for capacity expansion of power conversion technology $j$ in period $t\left(10^{6} \mathrm{US} \$ / \mathrm{GW}\right)$

$C P T_{j t}^{ \pm}=$units of electricity production per unit of capacity for power conversion technology $j$ in period $t(\mathrm{PJ} / \mathrm{GW})$

$E C P_{j t}^{ \pm}=$units of energy carrier per unit of electricity production for conversion technology $j$ in period $t(\mathrm{PJ} / \mathrm{PJ})$

$E M N_{t}^{ \pm}=\mathrm{NO}_{\mathrm{x}}$ emission allowance in period $\mathrm{t}$ (tonne)

$E M P_{t}^{ \pm}=\mathrm{PM}$ emission allowance in period $t$ (tonne)

$E M S_{t}^{ \pm}=\mathrm{SO}_{2}$ emission allowance in period $t$ (tonne)

OCS $S_{m_{s} t}^{ \pm}=$operation cost of control measure $m_{s}$ for $\mathrm{SO}_{2}$ emission in period $t$ (US\$/tonne)

$O C N_{m_{n} t}^{ \pm}=$operation cost of control measure $m_{n}$ for $\mathrm{NO}_{\mathrm{x}}$ emission in period $t$ (US\$/tonne)

$O C P_{m_{p} t}^{ \pm}=$operation cost of control measur $m_{p}$ for PM emission in period $t$ (US\$/tonne)

$R E S_{j t}^{ \pm}=$residual capacity of power conversion technology $j$ in period $t(\mathrm{GW})$

$U C E_{j t}^{ \pm}=$upper bounds for capacity expansion of power conversion technology $j$ in period $t(\mathrm{GW})$

$N O E_{j t}^{ \pm}=$unit of $\mathrm{NO}_{\mathrm{x}}$ emission per unit of electricity production for power conversion technology $j$ in period $t$ (tonne/ $\mathrm{GWh}$ )

$P M E_{j t}^{ \pm}=$unit of PM emission per unit of electricity production for power conversion technology $j$ in period $t$ (tonne/ GWh)

$S O E_{j t}^{ \pm}=$unit of $\mathrm{SO}_{2}$ emission per unit of electricity production for power conversion technology $j$ in period $t$ (tonne/ $\mathrm{GWh}$ )

$\eta_{m_{n} t}^{ \pm}=$average efficiency of $\mathrm{NO}_{\mathrm{x}}$ control measure $m_{n}(\%)$

$\eta_{m_{p} t}^{ \pm}=$average efficiency of PM control measure $m_{p}(\%)$

$\eta_{m_{s} t}^{ \pm}=$average efficiency of $\mathrm{SO}_{2}$ control measure $m_{s}(\%)$

\section{Decision variables:}

$X S_{i t}^{ \pm}=$energy resource $i$ supply in period $t(\mathrm{PJ})$ 
Table 1. Purchase Costs for Energy Resources Supply $\left(10^{6} \mathrm{US} \$ / \mathrm{PJ}\right)$

\begin{tabular}{|c|c|c|c|c|c|c|c|}
\hline \multirow{2}{*}{ Cost } & \multirow{2}{*}{$\mathrm{t}$} & \multirow{2}{*}{$\mathrm{q}$} & \multicolumn{5}{|c|}{ Energy supply } \\
\hline & & & Imported natural gas & Domestic natural gas & Imported coal & Domestic coal & Hydro \\
\hline Unit price & 1 & 1 & {$[7.00,8.00]$} & {$[6.00,7.00]$} & {$[4.20,5.00]$} & {$[3.50,4.00]$} & - \\
\hline \multirow{5}{*}{$C_{i q t}^{ \pm}$} & 2 & & {$[8.00,9.00]$} & {$[7.00,8.00]$} & {$[5.20,6.00]$} & {$[4.50,5.00]$} & - \\
\hline & 3 & & {$[9.00,10.00]$} & {$[8.00,9.00]$} & {$[6.20,7.00]$} & {$[5.50,6.00]$} & - \\
\hline & 1 & 2 & {$[5.50,6.50]$} & {$[4.50,5.60]$} & {$[3.00,4.00]$} & {$[2.50,3.20]$} & \\
\hline & 2 & & {$[6.50,7.50]$} & {$[5.50,6.60]$} & {$[4.00,5.00]$} & {$[3.50,4.20]$} & \\
\hline & 3 & & {$[7.50,8.50]$} & {$[6.50,7.60]$} & {$[5.00,6.00]$} & {$[4.50,5.20]$} & \\
\hline Setup cost & 1 & 1 & {$[[0.04,0.06]$} & {$[0.02,0.03]$} & {$[0.03,0.05]$} & {$[0.03,0.04]$} & - \\
\hline \multirow[t]{2}{*}{$K C_{i t}^{ \pm}$} & 2 & & {$[0.05,0.07]$} & {$[0.02,0.03]$} & {$[0.04,0.06]$} & {$[0.03,0.04]$} & 一 \\
\hline & 3 & & {$[0.06,0.08]$} & {$[0.02,0.03]$} & {$[0.05,0.07]$} & {$[0.03,0.04]$} & - \\
\hline Holding cost & 1 & 1 & {$[4.00,5.00]$} & {$[4.00,5.00]$} & {$[1.00,1.50]$} & {$[1.00,1.50]$} & - \\
\hline \multirow[t]{2}{*}{$H C_{i t}^{ \pm}$} & 2 & & {$[4.50,6.50]$} & {$[4.50,6.50]$} & {$[1.50,2.00]$} & {$[1.50,2.00]$} & - \\
\hline & 3 & & {$[5.00,7.00]$} & {$[5.00,7.00]$} & {$[2.00,2.50]$} & {$[2.00,2.50]$} & - \\
\hline Transportation cost & 1 & 1 & {$[8.50,9.50]$} & {$[3.50,4.00]$} & {$[6.00,7.00]$} & {$[2.00,3.00]$} & - \\
\hline \multirow[t]{2}{*}{$T C_{i t}^{ \pm}$} & 2 & & {$[9.00,10.00]$} & {$[4.00,4.50]$} & {$[7.00,8.00]$} & {$[3.00,4.00]$} & 一 \\
\hline & 3 & & {$[9.50,10.50]$} & {$[4.50,5.00]$} & {$[8.00,9.00]$} & {$[4.00,5.00]$} & - \\
\hline \multirow{3}{*}{$\begin{array}{l}\text { Upper bound for allow- } \\
\text { able energy supply (PJ) } \\
U X_{i t}^{ \pm}\end{array}$} & 1 & 1 & {$[130,160]$} & {$[65,80]$} & {$[260,300]$} & {$[150,170]$} & {$[30,50]$} \\
\hline & 2 & & {$[150,180]$} & {$[80,95]$} & {$[270,320]$} & {$[180,200]$} & {$[30,50]$} \\
\hline & 3 & & {$[170,200]$} & {$[95,100]$} & {$[280,360]$} & {$[210,220]$} & {$[30,50]$} \\
\hline
\end{tabular}

* Symbol "- - denotes the cost is not considered.

$X S_{i q t}^{ \pm}=$energy resource $i$ supply under different purchase batch in period $t(\mathrm{PJ})$

$X E_{j t}^{ \pm}=$continuous variables about the amount of capacity expansion of power conversion technology $j$ in period $t(j=1,2$, 3) $(\mathrm{GW})$

$A N O_{j m_{n} t}^{ \pm}=$amount of $\mathrm{NO}_{\mathrm{x}}$ generated from power conversion technology $j$ to be mitigated by control measure $m_{n}$ in period $t$ (tonne)

$A P M_{j m_{p} t}^{ \pm}=$amount of PM generated from power conversion technology $j$ to be mitigated by control measure $m_{p}$ in period $t$ (tonne)

$A S O_{j m_{s} t}^{ \pm}=$amount of $\mathrm{SO}_{2}$ generated from power conversion technology $j$ to be mitigated by control measure $m_{s}$ in period $t$ (tonne)

$Y_{\text {iqt }}^{ \pm}=$binary variables for identify which unit price for imported energy resource $i$ should be adopted in period $t$ ( $Y_{\text {iqt }}^{ \pm}=0 / 1$, $i=1,2,3,4)$

$Z_{j t}^{ \pm}=$binary variables for identifying whether or not a capacity expansion action of power conversion technology $j$ should be undertaken in period $\mathrm{t}\left(Z_{j t}^{ \pm}=0 / 1, j=1,2,3\right.$, )

$Q_{i t}^{ \pm}=$the best purchase batch for energy resource $i$ in period $t$ (PJ)

$f^{ \pm}=$expected system cost over the planning horizon $\left(10^{6}\right.$ US\$)

According to the proposed $0 \sim 1$ piecewise linearization method in subsection 2.2, model (12) can be converted into an IMILP model by introducing a number of binary variables, and then be transformed into two deterministic submodels corresponding to the lower and upper bounds of the objective function value, and solved by a two-step interactive method. The summarized solution steps for this model can be presented as follows:
Step 1: Formulate the IINP model [i.e. model (12)].

Step 2: Linearize model (12) by introducing a $0 \sim 1$ piecewise linearization approach.

Step 3: Transform the developed model in step 2 into two submodels, where $f^{-}$is desired since the objective is to minimize $f^{ \pm}$; formulate the first submodel which corresponds to $f^{-}$.

Step 4: Solve the $f^{-}$submodel and obtain solution of $X S_{i t k ~ o p t, q=1}^{-}, X S_{i t ~ o p t, q=2}^{-}, Y_{i 1 t o p t}^{-}, Y_{i 2 t ~ g p t}^{-}, Z_{j t ~ o p t}^{-}$and $\mu_{i t k o p t}^{-}$.

Step 5: Calculate $X S_{\text {it opt, } q=1}^{-}=\sum_{k=1}^{\infty} X S_{\text {itk opt, } q=1}^{-}$, and $X S_{\text {it opt }}^{-}=$ $\sum X S_{\text {itk opt, } q=1}^{-}+X S_{\text {it opt }, q=2}^{-}$.

Step 6: Formulate the second submodel which corresponds to $f^{+}$.

Step 7: Solve the $f^{+}$submodel and obtain solution of $X S_{i t k ~ o p t, q=1}^{+}, X S_{\text {it opt, } q=2}^{+}, Y_{i 1 t o p t}^{+}, Y_{i 2 t \text { opt }}^{+}, Z_{j t ~ o p t}^{+}$and $\mu_{\text {itk opt }}^{+}$.

Step 8: Calculate $X S_{\text {it opt, } q=1}^{+}=\sum_{k=1}^{s} X S_{\text {itk opt, } q=1}^{+}$, and $X S_{\text {it opt }}^{+}=$ $\sum X S_{\text {itk opt }, q=1}^{+}+X S_{\text {it opt, } q=2}^{+}$.

Step 9: Combine the two submodels' solutions to obtain the solution of model (12):

$$
\begin{aligned}
& f_{\text {iopt }}^{ \pm}=\left[f_{\text {iopt }}^{-}, f_{\text {iopt }}^{+}\right] \\
& X S_{\text {it opt }}^{ \pm}=\left[X S_{\text {it opt }}^{-}, X S_{\text {it opt }}^{+}\right], \forall i, t \\
& Y_{\text {ilt opt }}^{ \pm}=\left[Y_{\text {ilt opt }}^{-}, Y_{\text {ilt opt }}^{+}\right], \forall i, t \\
& Y_{i 2 t o p t}^{ \pm}=\left[Y_{\text {i2t opt }}^{-}, Y_{i 2 t o p t}^{+}\right], \forall i, t \\
& Z_{j t o p t}^{ \pm}=\left[Z_{j t o p t}^{-}, Z_{j t o p t}^{+}\right], \forall j, t
\end{aligned}
$$


Table 2. Economic and Technological Data for Different Power Conversion Technologies

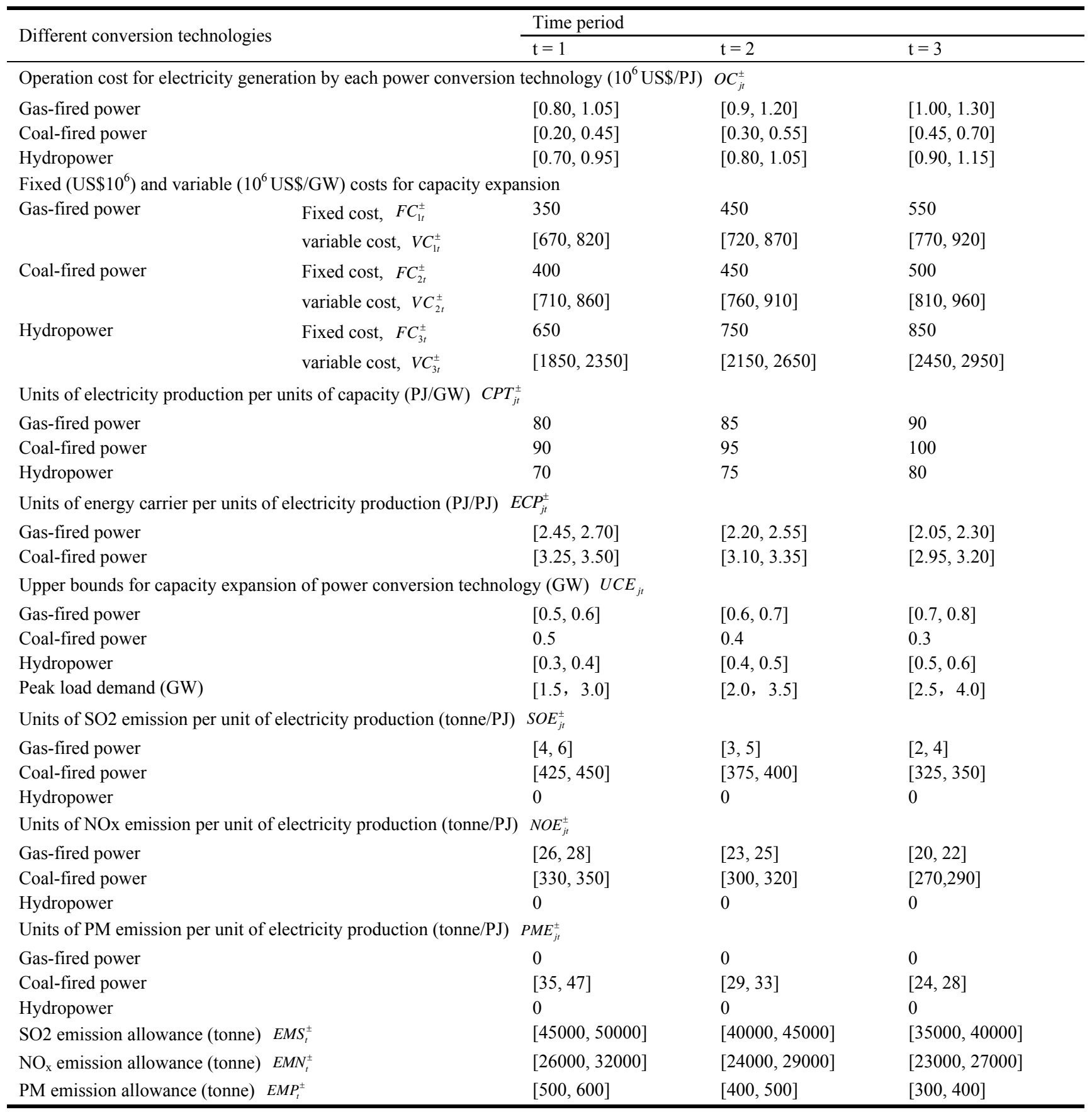

$\mu_{i t k ~ o p t}^{ \pm}=\left[\mu_{i t k ~ o p t}^{-}, \mu_{i t k ~ o p t}^{+}\right], \forall i, t, k$

\section{Step 10: Stop.}

In this study system, multiple energy resources supply schemes with varied unit prices and purchase batches, multiple conversion technologies, multiple end-users and multiple pollution mitigation strategies are considered. Table 1 shows related purchase costs for energy resource supply and the upper bound of energy resources supply allowance, which are estimated according to Statistics Bureau of Hebei and the survey report (Hebei Statistics Bureau, 2011). Resources import from other regions usually has higher costs, which is always limited by the availability of resources supply allowance from other regions and different purchase schemes. Two unit prices (local or imported) in accordance with different purchase batches per time for same energy resource supply are considered in this study. 
M. Q. Suo et al. / Journal of Environmental Informatics 22(1) 49-67 (2013)

Table 3. Solutions of Energy Resources Supply Obtained from the IINP Model

\begin{tabular}{|c|c|c|c|c|c|c|c|c|c|}
\hline \multirow{2}{*}{ Resources } & \multicolumn{3}{|c|}{ Optimal resources supply (PJ) } & \multicolumn{6}{|c|}{$q=1 \leftarrow$ Binary variables $Y_{i q t}^{ \pm} \rightarrow q=2$} \\
\hline & $\mathrm{t}=1$ & $t=2$ & $t=3$ & $\mathrm{t}=1$ & $\mathrm{t}=2$ & $t=3$ & $\mathrm{t}=1$ & $\mathrm{t}=2$ & $\mathrm{t}=3$ \\
\hline Imported natural gas & {$[130,160]$} & {$[71.50,180]$} & {$[0,181.21]$} & 0 & 1 & 1 & 1 & 0 & 0 \\
\hline Domestic natural gas & {$[65,80]$} & {$[80,95]$} & {$[95,100]$} & 1 & 1 & 1 & 0 & 0 & 0 \\
\hline Imported coal & {$[260,300]$} & {$[270,320]$} & {$[280,306.55]$} & 0 & 0 & 0 & 1 & 1 & 1 \\
\hline Domestic coal & {$[150,170]$} & {$[180,200]$} & {$[210,220]$} & 0 & 0 & 0 & 1 & 1 & 1 \\
\hline Hydro & {$[30,50]$} & {$[7.70,50]$} & {$[20.80,48.50]$} & - & - & - & - & - & - \\
\hline
\end{tabular}

* Symbol "-" denotes the cost is not considered.

Table 2 presents the economic and technological data for different power conversion technologies. In this table, the capacity expansion costs and technological data are estimated based on the data from the company of Datang WuAn, while the operation cost is estimated according to different power conversion technologies and capacities. Based on the data from the Environmental Report of Hebei (Yin, 2011), units of all the pollutants emissions per unit of electricity production from these power plants can be estimated. In order to improve local air quality, the pollution emissions allowances will gradually decrease in three planning periods to comply with the environmental policy, which are estimated based on the Plan of main pollutant total emission reduction for WuAn in 2011 (Zhang, 2011). Besides, soda ash scrubber (SAS), wet limestone scrubber (WLS) and lime spray dryer (LSD) are employed to control the amount of $\mathrm{SO}_{2}$ emission, while selective catalytic reduction (SCR) and selective non-catalytic reduction (SNCR) are used to reduce the amount of $\mathrm{NO}_{\mathrm{x}}$ emission, and fabric filiter/baghouse (BH), electrostatic precipitator (ESP) and wet collector (WC) are selected to alleviate the amount of PM emission.

\section{Results and Discussion}

\subsection{Result Analysis}

Table 3 shows the solutions of energy resources supply and binary variables for identifying different purchase prices obtained from the IINP model. Since the most electricity generation is from coal-fired power plant followed with natural gas-fired power plant and hydropower plant, the main resources supply is coal, and then is natural gas and last is hydro. The results demonstrate that most of the resources supply is from local region, and imported resources are responsible for the rest supply in case of local resources shortage. For example, for natural gas-fired power plant, local natural gas supply would be $[65,80]$, [80, 95], and $[95,100] \mathrm{PJ}$ in the whole planning period, individually, which reach their respecttive upper bounds of allowable supply and follow an increased trend with the demand increment; in comparison, imported natural gas would not have obvious increasing or decreasing trend, being [130, 160], [71.50, 180], and [0, 181.21] $\mathrm{PJ}$ in periods 1,2 and 3, respectively, which is due to different surplus natural gas supply in previous periods. In period 1, since the initial natural gas storage is zero, both of local and imported natural gas supply have reached the upper bounds of allowable supply; in periods 2 and 3, due to the surplus natural gas supply in periods 1 and 2, relatively, less natural gas would be imported with the increasing demand and local natural gas supply, particularly the lower bound of imported natural gas supply. The similar trend also can be found in coal-fired power plant. For hydropower plant, the optimized water supply quantity would be [7.70,50] $\mathrm{PJ}$ in period 2 and $[20.80,48.50]$ $\mathrm{PJ}$ in period 3 resulted from various surplus water supply in periods 1 and 2 , respectively.

In addition, in accordance with different energy resources supply, varied unit prices should be determined to minimize the system cost, which can be reflected by the binary variable of $Y_{i q t}^{ \pm}$. In Table 3, if $Y_{i t, q=1}^{ \pm}=1$, the higher unit price would be undertaken followed with less purchase batch per time; otherwise, the lower unit price would be undertaken followed with more purchase batch per time $\left(Y_{i t, q=1}^{ \pm}=0\right.$ and $\left.Y_{i t, q=2}^{ \pm}=1\right)$. For example, the purchase unit price for imported natural gas supply would be $[5.50,6.50] \times 10^{6},[8.00,9.00] \times 10^{6}$ and $[9.00$, $10.00] \times 10^{6} \mathrm{US} \$ / \mathrm{PJ}$ over the planning periods, respectively, while they are $[6.00,7.00] \times 10^{6},[7.00,8.00] \times 10^{6}$ and $[8.00$, $9.00] \times 10^{6} \mathrm{US} \$ / \mathrm{PJ}$ for local natural gas supply in the whole planning period, individually. The unit prices for coal supply from local and other regions can be similarly analyzed based on the results shown in Table 3. The results indicate that different energy resources would be imported with varied unit prices under different local energy resources supply abilities and demand levels.

In accordance with the total purchase quantities and different unit prices for energy resources supply, the adopted purchase batches per time obtained from the proposed IINP model are depicted in Figure 3. Actually, there is a variety of factors influence the purchase batch, such as unit price, setup cost, holding cost, storage capacity, as well as the total purchase quantity. In period 1, the purchase batch would be [9, 10], [1.80, 2.19], [14, 16], and [11, 12] PJ for imported natural gas, domestic natural gas, imported coal and domestic coal, respectively; in period 2, the purchase batch would be [2.82, 4.40], [1.89, 2.09], [14, 16], and [11, 12] PJ for imported and domestic natural gas and coal, individually; in period 3, the purchase batch would be [0, 4.55], [1.95, 2.07], [14, 16], and $[11,12]$ PJ for imported natural gas, domestic natural gas, imported coal and domestic coal, respectively. Through comparing the demarcation purchase batch $([9,10],[6,8],[14,16]$ 


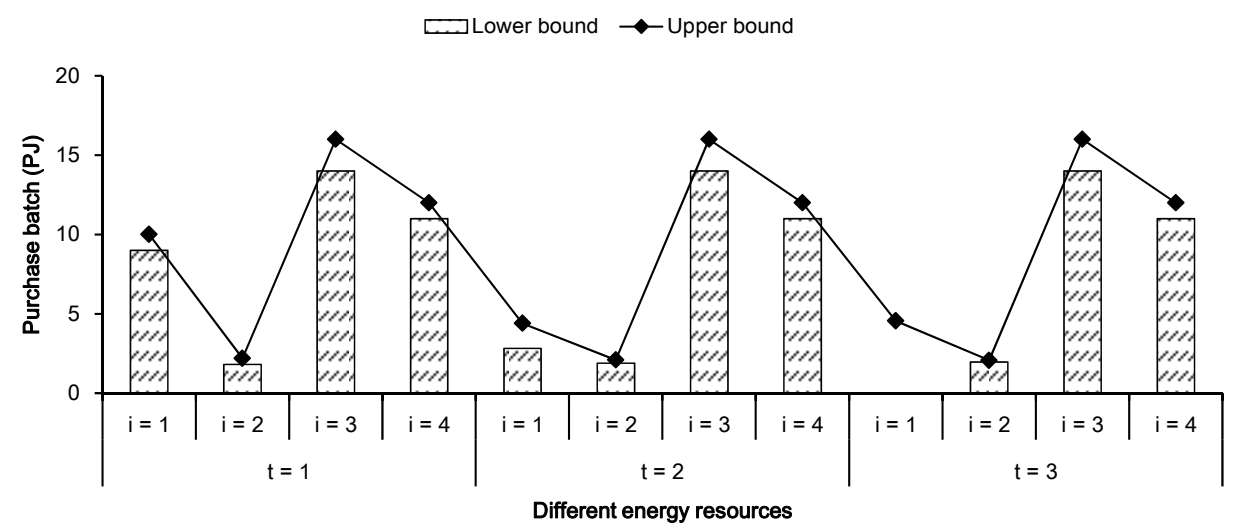

Figure 3. Solution of purchase batch obtained from the IINP model.

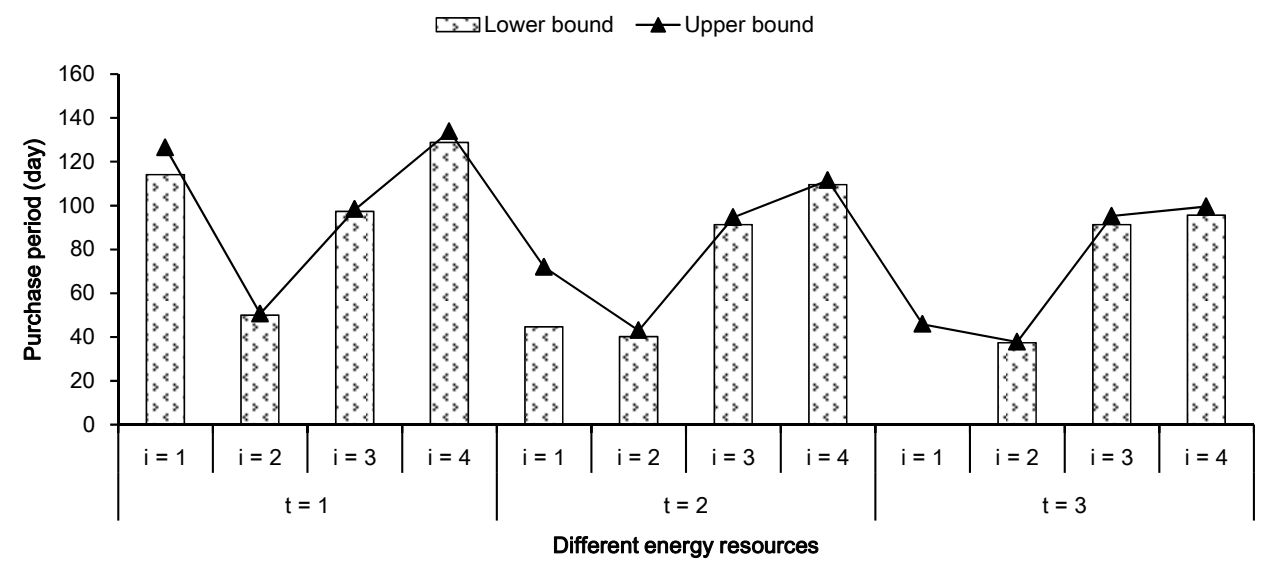

Figure 4. Solution of purchase period obtained from the IINP model.

Table 4. Solutions of Power Generation Obtained from the IINP Model

\begin{tabular}{|c|c|c|c|}
\hline \multirow{2}{*}{$\begin{array}{l}\text { Conversion } \\
\text { Technologies }\end{array}$} & \multicolumn{3}{|l|}{ Time period } \\
\hline & $t=1$ & $t=2$ & $t=3$ \\
\hline \multicolumn{4}{|c|}{ Binary variables $Z_{j t}^{ \pm}$} \\
\hline NGP & 1 & {$[0,1]$} & {$[0,1]$} \\
\hline CFP & {$[0,1]$} & 1 & 1 \\
\hline HP & {$[0,1]$} & 0 & 0 \\
\hline \multicolumn{4}{|c|}{ Amount of Capacity expansion $X E_{j t}^{ \pm}(\mathrm{GW})$} \\
\hline NGP & {$[0.50,0.60]$} & {$[0,0.37]$} & {$[0,0.37]$} \\
\hline CFP & {$[0,0.06]$} & 0.13 & 0.13 \\
\hline HP & {$[0,0.40]$} & 0 & 0 \\
\hline \multicolumn{4}{|c|}{ Amount of Power generation (PJ) } \\
\hline NGP & {$[152.48,190.08]$} & {$[145.48,271.00]$} & {$[143.54,335.13]$} \\
\hline CFP & {$[409.50,459.90]$} & {$[450.50,505.93]$} & {$[490.00,550.73]$} \\
\hline HP & {$[18.20,46.20]$} & {$[19.50,49.50]$} & {$[20.80,52.80]$} \\
\hline
\end{tabular}

NGP: Natural gas-fired power, CFP: Coal-fired power, HP: Hydropower.

and $[11,12] \mathrm{PJ}$ for imported natural gas, domestic natural gas, imported coal and domestic coal, respectively) and economic purchase batch, several purchase schemes have adopted the demarcation purchase batch with lower unit price rather than the economic purchase batch with higher unit price, such as the natural gas supply from importing in period 1, and the coal supply from domestic and other regions in three planning periods. It can be concluded that not all the economic purchase batch are the best purchase batch which should be decided by the total purchase costs, varied unit prices and other costs.

According to Suo et al. (2011), the purchase period for every resource in each planning period can be obtained based on the energy resources supply and purchase batch per time. The purchase period means a cycle length from one purchase scheme to the next scheme, which is a time range and equals to the purchase batch divided by the energy resources supply and then multiplied by each planning period (five years $\times 365$ day/year). Figure 4 displays the purchase period for different energy resources supply, which is helpful for in-depth analysis of the selected purchase schemes and specific purchase process. Because of the long planning period (each period with five years), a lot of energy resources supply and the storage capacity limitation, the study system may purchase energy resources many times, and thus there may be a time interval between every two purchase times, which is actual the purchase period. In Figure 4, the value of 0 does not mean there is no time interval between every two purchase times, but is obtained from the zero supply. The result indicates that if the energy resources supply and the purchase batch are much larger and smaller, respectively, the purchase period would be smaller; conversely, if the energy resources supply 

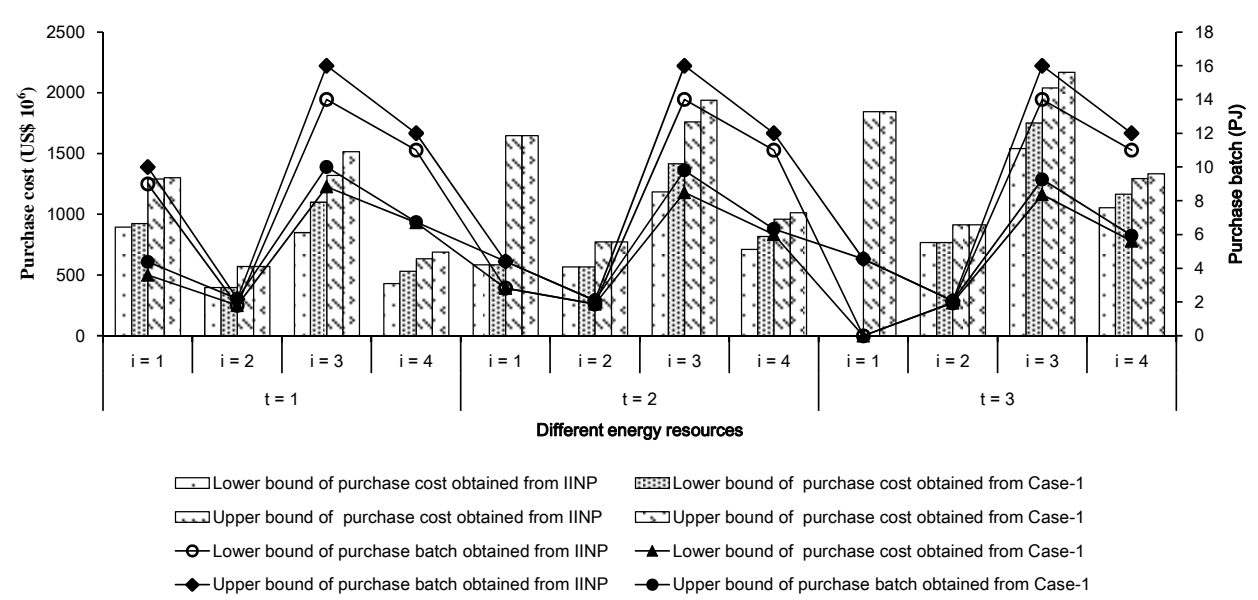

Figure 5. Purchase costs comparison for resources supply between IINP and Case-1 ("Case-1" denotes the purchase schemes taken by the economic purchase quantity).
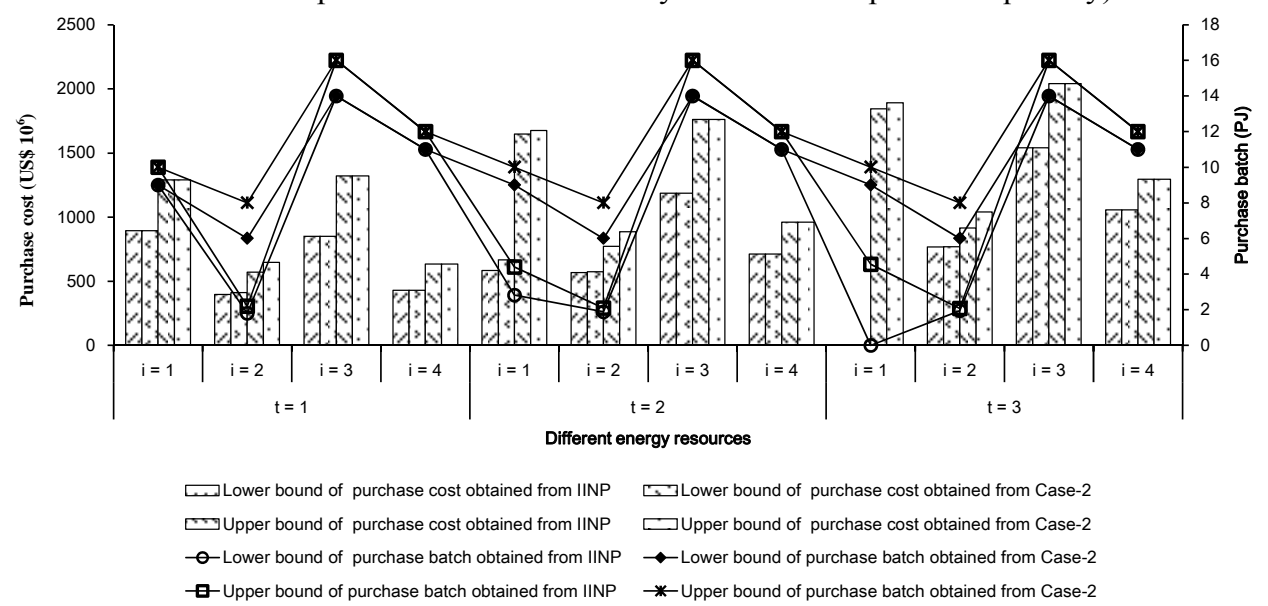

Figure 6. Purchase costs comparison for resources supply between IINP and Case-2 ("Case-2" denotes the purchase schemes taken at the demarcation point).

and the purchase batch are much smaller and larger, respecttively, the purchase period would be larger. Moreover, if the purchase period becomes smaller, the time interval would be narrow between every two purchase times, leading to the purchase frequency increase; and if the purchase period becomes larger, the time interval would be broaden, resulting in the purchase frequency decrease.

Table 4 presents the solution of capacity expansion schemes and the amount of power generation for three conversion technologies over the whole planning period under different electricity demands. In this table, the solution of capacity expansion schemes can be obtained directly by the proposed IINP model. The amount of power generation by different conversion technologies is calculated based on the different capacity expansion schemes by $\sum_{j=1}^{2} \sum_{t=1}^{3}\left(R E S_{j t}^{ \pm}+\sum_{t=1}^{t} X E_{j t}^{ \pm}\right) C P T_{j t}^{ \pm} E C P_{j t}^{ \pm}$.

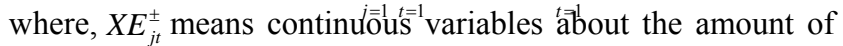
capacity expansion of power conversion technology $j$ in period $t(\mathrm{GW}) ; R E S_{j t}^{ \pm}$denotes residual capacity of power conversion technology $j$ in period $t(\mathrm{GW}) ; C P T_{j t}^{ \pm}$indicates units of electricity production per unit of capacity for power conversion technology $j$ in period $t(\mathrm{PJ} / \mathrm{GW}) ; E C P_{j t}^{ \pm}$means units of energy carrier per unit of electricity production for conversion technology $j$ in period $t(\mathrm{PJ} / \mathrm{PJ})$. Generally, shortages would happen with the electricity demands constantly increasing, and a capacity expansion activate would be undertaken to avoid insufficient electricity supply. Wherein, the binary variable of $Z_{j t}^{ \pm}$ denotes which conversion technology whether need to be expanded in period t. The value of 1 indicates the capacity expansion should be undertaken while the value of 0 means not. For example, the capacity expansion would be adopted for natural gas-fired power plant in period 1, periods 2 and 3 under the optimistic condition (the upper bound); for coalfired power plant, it should expand its capacity in period 1 under the optimistic condition and in periods 2 and 3 under optimistic and pessimistic conditions; for hydropower plant, it only needs to expand the capacity in period 1 under the optimistic condition. In accordance with the varied values of binary variables, the specific amounts of capacity expansion for natural gas-fired power plant, coal-fired power plant and hydropower plant can be seen in Table 4. In comparison, the amounts of capacity expansion for natural gas-fired power plant and hydropower plant are both larger than the one for coal-fired power plant in period 1, which could be affected by 
M. Q. Suo et al. / Journal of Environmental Informatics 22(1) 49-67 (2013)

Table 5. Solutions of Different Costs Obtained from the IINP Model

\begin{tabular}{llll}
\hline \multirow{2}{*}{ Different costs $\left(\mathrm{US} \$ 10^{6}\right)$} & \multicolumn{3}{c}{ Time period } \\
\cline { 2 - 4 } & $\mathrm{t}=1$ & $\mathrm{t}=2$ & $\mathrm{t}=3$ \\
\hline Purchase cost & {$[2573.76,3817.42]$} & {$[3051.93,5144.10]$} & {$[3364.39,6093.82]$} \\
Transportation cost & {$[3192.50,4450.00]$} & {$[3393.50,5587.50]$} & {$[3507.50,6261.66]$} \\
Expansion cost & {$[683.64,2883.60]$} & {$[548.58,1340.19]$} & {$[606.36,1515.25]$} \\
Operation cost for power generation & {$[216.63,450.43]$} & {$[281.68,655.43]$} & {$[382.76,881.90]$} \\
Operation cost for pollution emission & {$[14.05,22.98]$} & {$[15.09,24.05]$} & {$[15.40,25.51]$} \\
System cost $f_{\text {opt }}^{ \pm}\left(\mathrm{US} \$ 10^{6}\right)$ & {$[21847.78,39153.84]$} & & \\
\hline
\end{tabular}

the air pollutants limitations and the purchase costs; in periods 2 and 3, due to the increment of electricity demand and the allowable resources supply, the amount of capacity expansion for coal-fired power plant is higher than the one for natural gas-fired power plant, while there is no capacity expansion for hydropower plant. It can be concluded that the capacity expansion schemes are affected by not only the air pollutants limitations and purchase costs but also the electricity demand and allowable resources supply.

Table 5 shows the solution of system cost obtained from IINP method during the whole planning horizon. In this study, the system cost includes purchase and transportation costs for energy resources supply, expansion cost for different conversion technologies, and operation costs for power generation and air pollution emission, which is affected by many factors, such as the market flection, transportation tools, different power generation, and the amounts of air pollutants and pollutions mitigation efficiencies by varied conversion technologies. Solution of the objective function ( $f_{\text {opt }}^{ \pm}=U S \$[21847.78$, $39153.84] \times 10^{6}$ ) offers two extreme values of the net system cost. With the actual values of the variables and/or modeling parameters change within their two bounds, the system cost would vary accordingly from $f_{\text {opt }}^{-}$to $f_{\text {opt }}^{+}$with different violation-risk levels. In addition, according to the five different costs and system cost in Table 5, it can be found that the purchase cost takes a large proportion in the total system cost, which means that the purchase cost for energy resources supply would affect the total system cost in a great degree. Based on Equation (1), it is known that the purchase cost mainly depends on the total purchase quantity, unit price and purchase batch. Therefore, it is necessary to analyze how different unit prices and purchase batches influence the purchase cost under certain purchase quantity.

\subsection{Discussion}

In this study, two unit prices for different energy resources supply are considered. Varied unit prices are followed with different purchase batches, which lead to different purchase schemes, and thus could affect the electricity generation activates and total system cost. Case- 1 denotes all the purchase schemes for different energy resources supply adopt the economic purchase batch as the purchase batch followed with higher unit price, calculated by Equation (4). Case-2 represents the purchase schemes for all energy resources supply employ the value of demarcation point as the purchase batch associated with lower unit price, obtained by Equation (1).
Figure 5 shows the purchase costs comparison for resources supply between IINP and Case-1, where histograms represent the purchase costs for imported natural gas supply, local natural gas supply, imported coal supply and local coal supply, and line charts denote the associated purchase batches. The result indicates that the purchase costs for all the energy resources supply obtained from IINP are smaller than or equivalent to the purchase costs obtained from Case- 1 during the whole planning period. For example, in period 1, the purchase costs for imported natural gas supply, imported coal supply and local coal supply from IINP (US\$[895.58, 1290.96] $\times 10^{6}$, $\mathrm{US} \$[850.58,1320.94] \times 10^{6}$ and US\$[430.41, 634.57] $\times 10^{6}$, respectively) are smaller than the purchase costs from Case-1, being US $\$[924.42,1301.91] \times 10^{6}, \mathrm{US} \$[1100.83,1515.00] \times$ $10^{6}$ and US $\$[531.71,690.10] \times 10^{6}$, respectively, while the purchase costs for local natural gas supply from IINP and Case- 1 are same, being US\$[397.21, 570.95] $\times 10^{6}$. In addition, in period 1 , the purchase batches for imported natural gas supply, imported coal supply and local coal supply from IINP are [9, 10], [14, 16], and [11, 12] PJ, respectively, which are associated with lower unit prices and higher than the purchase batches from Case-1 ([3.61, 4.38], [8.83, 10.00] and $[6.71,6.73] \mathrm{PJ})$ associated with higher unit prices. Both of the purchase batches for local natural gas supply from IINP and Case-1 are [1.80, 2.19] PJ followed with higher unit price in period 1. Comparisons for purchase costs and purchase batches for resources supply between IINP and Case- 1 in periods 2 and 3 can be similarly interpreted according to the results shown in Figure 5.

Figure 6 depicts the purchase costs comparison for resources supply between IINP and Case-2. It can be seen that the purchase costs for all imported natural gas supply, local natural gas supply, imported coal supply and local coal supply obtained from IINP are smaller than or equivalent to the purchase costs obtained from Case- 2 over the whole planning period. For example, in period 2, the purchase costs for imported and local natural gas supply determined by IINP (US $\$[584.68$, $1648.62] \times 10^{6}$ and US $\left.\$[568.49,773.61] \times 10^{6}\right)$ are smaller than the purchase costs from Case-2, being US\$[667.65, $1676.26] \times 10^{6}$ and US\$[575.27, 887.36] $\times 10^{6}$, respectively, while the purchase costs for imported and local coal supply from IINP and Case-2 are same, being US\$[1185.77, 1761.20] $\times 10^{6}$ and US $\$[712.99,960.67] \times 10^{6}$, respectively. Moreover, in period 2, the purchase batches for imported and local natural gas supply determined by IINP are [2.82, 4.40] and [1.89, 2.09] PJ followed with higher unit prices, respectively, which 
are smaller than the purchase batches obtained from Case-2, being $[9.00,10.00]$ and $[6.00,8.00] \mathrm{PJ}$ associated with lower unit prices, respectively. Both of the purchase batches for imported and local coal supply from IINP and Case-2 are $[14.00,16.00]$ and $[11.00,12.00] \mathrm{PJ}$ in accordance with lower unit prices, individually. Comparisons for purchase costs and purchase batches for resources supply between IINP and Case2 in periods 1 and 3 can be similarly analyzed based on the results presented in Figure 6.

Based on the above descriptions, it can be concluded that the purchase costs for energy resources supply obtained from IINP are the lowest among IINP, Case-1 and Case-2. Accordingly, the purchase batches determined by IINP are in the middle of the purchase batches obtained from Case- 1 and Case-2 during the whole planning period. This comparison result illustrates that only the adoption of economic purchase batch (Case-1) or the employment of lower unit price (Case-2) cannot guarantee the minimum purchase cost. Since the adoption of economic purchase batch may increase the purchase frequency and thus increase the setup cost, and the employment of lower unit price associated with larger purchase batch may increase the storage and thus increase the holding cost, both of them could lead to the increment of purchase cost. Therefore, the purchase scheme cannot be decided simply depending on purchase unit price or purchase batch, it needs to comprehensively consider the purchase batch and unit price for solving the quantity discount problems. The above analyses demonstrate a tradeoff between purchase batch and unit price, and indicate the proposed IINP model is an effective method to balance the purchase batch and unit price as well as other influenced factors under uncertainty. In addition, this method also does not need the step by step comparison to decide the best purchase scheme, avoiding a lot of tedious and time consuming calculations.

\section{Conclusions}

In this study, an inexact inventory nonlinear programming (IINP) model has been advanced for solving energy resources supply problem under multiple unit prices and uncertain demands in an electric-power system. In IINP, interval-parameter programming, inventory theory and nonlinear programming have been integrated into a general optimization framework. The developed method can not only help to identify optimum purchase scheme with minimized system cost but also can provide specific purchase process, such as the purchase batch, unit price and purchase period under different demands. In addition, it can also explicitly handle system uncertainties expressed as intervals and effectively address nonlinearity in the objective function. In its solution process, the IINP model can first be linearized by $0 \sim 1$ piecewise linearization approach, and then be transformed into two deterministic submodels associated with the lower and upper bounds of the objective function value. Consequently, interval solutions with reasonable purchase batch and unit price as well as capacity expansion can be generated by solving the two submodels sequentially.
The proposed IINP has been applied to a case of an electric power system planning, where various purchase schemes associated with different unit prices, multiple capacity expansion options and varied electricity demands are considered based on different energy resources and environmental management policies. The solutions of continuous variables are generated to help determine the amounts of energy resources supply, capacity expansion and power generation; the results of binary variables display the selection of purchase schemes and facility expansion, where a variety of alternatives are offered; in addition, it can also provide the best purchase batch, purchase period and associated unit price with minimized purchase cost under certain energy resources supply, and thus help in-depth analyses of the tradeoff between purchase batch and unit price. In summary, the solutions obtained are effective in supporting (a) determination of reasonable energy resources supply scheme with global solutions, and elimination of step by step comparisons among many purchase schemes, (b) adjustment or justification purchase batches of energy resources supply and facility expansion for powerconversion technologies under different demand levels, and (c) integration of policies regarding energy resources supply, economy objective and environmental protection for in-depth analysis of tradeoff between purchase batch and unit price as well as system cost and risk.

The developed method can not only directly handle facility expansion under uncertainty but also generate reasonable purchase batches and periods associated with different unit prices and minimum purchase costs, and thus provide effecttive schemes for supporting electricity generation. As a first attempt, only the quantity discount problem in inventory theory is considered in this study. Consequently, the developed method does not consider the more complex inventory issues, and does not combine with stochastic programming to study the specific relationship between energy supply and consumption in electric power systems. On the other hand, there are some limitations and assumptions of this method applied to the real case study. For example, it only considers the quantity discount problems where different purchase batch is in accordance with varied unit price, without considering the price inflation in the planning period. Moreover, the developed method does not consider the specific distributions of different energy resources supply, which could change electricity generation plans and capacity expansion schemes. All of these may make the IINP method less practical, resulting in ineffectiveness in obtaining the expected schemes for decision makers in real case studies. In conclusion, the developed IINP method can be further improved by introducing more progressive and/or complex optimization technologies (such as stochastic linear programming, fuzzy linear programming and multi-stage linear programming) to study more complicated inventory problems in electric power systems.

Acknowledgments. This research was supported by the National Natural Science Foundation for Distinguished Young Scholar (Grant No. 51225904), the Major Project Program of the Natural Sciences Foundation (Grant No. 51190095), the Program for Innovative Research Team in University (IRT1127), and the Key Project of the 
Ministry of Education (No. 311013). The authors are grateful to the editors and the anonymous reviewers for their insightful comments and suggestions.

\section{References}

Afshar, K., and Bigdeli, N. (2011). Data analysis and short term load forecasting in Iran electricity market using singular spectral analysis (SSA), Energy, 36(5), 2620-2627. http://dx.doi.org/10. 1016/ j.energy.2011.02.003

Ahmed, S., and Sahinidis, N.V. (2003). An approximation scheme for stochastic integer programs arising in capacity expansion, Oper. Res., 51(3), 461-471. http://dx.doi.org/10.1287/opre.51.3.461.149 60

Arnold, J., Minner, S., and Ediam, B. (2009). Raw material procurement with fluctuating prices, Int. J. Prod. Econ., 121(2), 353364. http://dx.doi.org/10.1016/j.ijpe.2007.02.038

Arsenault, E., Bernard, J.T., Carr, C.W., and Genest-Laplante, E. (1995). A total energy demand model of Québec: Forecasting properties, Energ. Econ., 17(2), 163-171. http://dx.doi.org/ 10.10 16/0140-9883(94)00003-Y

Birant, D. (2011). Comparison of Decision Tree Algorithms for Predicting Potential Air Pollutant Emissions with Data Mining Models, J. Environ. Inform., 17(1), 46-53. http://dx.doi.org/10.3808/ jei.201100186

Carpinteiro, O.A.S., Leme, R.C., de Souza, A.C.Z., Pinheiro, C.A.M., and Moreira, E.M. (2007). Long-term load forecasting via a hierarchical neural model with time integrators, Electr. Pow. Syst. Res., 77(3-4), 371-378. http://dx.doi.org/10.1016/j.epsr.2006.03.014

Christodoulakis, N.M., Kalyvitis, S.C., Lalas, D.P., and Pesmajoglou, S. (2000). Forecasting energy consumption and energy related $\mathrm{CO}_{2}$ emissions in Greece: an evaluation of the consequences of the Community Support Framework II and natural gas penetration, Energ. Econ., 22(4), 395-422. http://dx.doi.org/10.1016/S0140-988 3(99)00040-7

Dale, M. (2012) Meta-analysis of non-renewable energy resource estimates, Energ. Policy, 43, 102-122. http://dx.doi.org/10.1016/j. enpol.2011.12.039

Dong, F., Chowdhury, B.H., and Crow, M.L. (2005). Improving voltage stability by reactive power reserve management. IEEE T, Power Syst., 20(1), 338-345. http://dx.doi.org/10.1109/TPWRS.20 04.841241

EI Saadany, A.M.A., and Jaber, M.Y. (2010). A production/remanufacturing inventory model with price and quality dependent return rate, Comput. Ind. Eng., 58(3), 352-362. http://dx.doi.org/10.1016 /j.cie.2009.01.017

Fallahi, A., Ebrahimi, R., and Chaderi, S.F. (2011). Measuring efficiency and productivity change in power electric generation management companies by using data envelopment analysis: A case study, Energy, 36(11), 6398-6405. http://dx.doi.org/10.1016/j.ener gy.2011.09.034

Fan, Y.R., and Huang, G.H. (2012). A Robust Two-Step Method for Solving Interval Linear Programming Problems within an Environmental Management Context, J. Environ. Inform., 19(1):1-9. http://dx.doi.org/10.3808/jei.201200203

Gupta, D., Hill, A.V., and Bouzdine-Chameeva, T. (2006). A pricing model for clearing end-of-season retail inventory, Eur. J. Oper. Res., 170(2), 518-540. http://dx.doi.org/10.1016/j.ejor.2004.07.048

Hammami, A., Burlat, P., and Campagne, J.P. (2003). Evaluating orders allocation within networks of firms, Int. J. Prod. Econ., 86(3), 233-249. http://dx.doi.org/10.1016/S0925-5273(03)00066-5

Handan Statistics Bureau (2011). Handan energy supply and consumption, Handan, Hebei, China [in Chinese].

Hebei Statistics Bureau (2011). Hebei energy supply and consum- ption, Hebei, China [in Chinese]

He, X.P., Liu, X.Y., and Lin, Y.P. (2009). Electricity demand forecast in the urbanization process of China, Economic Research (China), $1,118-130$.

Hsu, C.C., and Chen, C.Y. (2003). Regional load forecasting in Taiwan - applications of artificial neural networks, Energ. Convers Manage., 44(12), 1941-1949. http://dx.doi.org/10.1016/S0196-89 04(02)00225-X

Hsu, G.J.Y., and Chou, F.Y. (2000) Integrated planning for mitigating $\mathrm{CO}_{2}$ emissions in Taiwan: a multi-objective programming approach, Energ. Policy, 28(8), 519-523. http://dx.doi.org/10.1016/ S0301- 4215(00)00006-9

Huang, G.H., and Cao, M.F. (2011). Analysis of solution methods for interval linear programming, J. Environ. Inform., 17(2), 54-64. http://dx.doi.org/10.3808/jei.201100187

Hunt, J.G., Judge, G., and Ninomiya, Y. (2003).Underlying trends and seasonality in UK energy demand: a sectoral analysis, Energ. Econ., 25(1), 93-118. http://dx.doi.org/10.1016/S0140-9883(02)00 $072-5$

Jafar, A.H., Al-Amin, A.Q., and Siwar, C. (2008). Environmental impact of alternative fuel mix in electricity generation in Malaysia, Renew. Energ., 33(10), 2229-2235. http://dx.doi.org/10.1016/j.ren ene.2007.12.014

Jannuzzi, G.D., and Schipper, L. (1991). The structure of electricity demand in the Brazilian household sector, Energ. Policy, 19(9), 879-891. http://dx.doi.org/10.1016/0301-4215(91)90013-E

Jónsson, T., Pinson, P., and Madsen, H. (2010). On the market impact of wind energy forecasts, Energ. Econ., 32(2), 313-320. http://dx. doi.org/10.1016/j.eneco.2009.10.018

Khouja, M. (2001). The effect of large order quantities on expected profit in the single-period model, Int. J. Prod. Econ., 72(3):227235. http://dx.doi.org/10.1016/S0925-5273(00)00150-X

Kim, Y.J., and Hwang, H. (2008). Incremental discount policy for taxi fare with price-sensitive demand, Int. J. Prod. Econ., 112(2), 895-902. http://dx.doi.org/10.1016/j.ijpe.2007.08.001

Kukreja, A., and Schmidt, C.P. (2005). A model for lumpy demand parts in a multi-location inventory system with transshipments, Comput. Oper. Res., 32(8), 2059-2075. http://dx.doi.org/10. 1016/j. cor.2004.01.007

Kumar, U., and Jain, V.K. (2010). Time series models (Grey-Markov, Grey Model with rolling mechanism and singular spectrum analysis) to forecast energy consumption in India, Energy, 35(4), 1709-1716. http://dx.doi.org/10.1016/j.energy.2009.12.021

Laherrere J. (2001). Estimates of oil reserves, EMF/IEA/IEW meeting IIASA, Laxenburg, Austria, June 19, 2001.

Laherrere J. (2004). Oil and natural gas resource assessment: production growth cycle models, Encyclopedia of Energy, 617-631. http://dx.doi.org/10.1016/B0-12-176480-X/00267-9

Lazaroiu, Gh., Zissulescu, E., Sandu, M., and Roscia, M. (2007). RETRACTED: Electron beam non-thermal plasma hybrid system for reduction of NOx and SOx emissions from power plants, Energy, 32(12), 2412-2419. http://dx.doi.org/10.1016/j.energy.200 7.05 .012

Lazzaretto, A., Toffolo, A., Morandin, M., and von Spakovsky, M.R. (2010). Criteria for the decomposition of energy systems in local/global optimizations, Energy, 35(2), 1157-1163. http://dx.doi. org/10.1016/j.energy.2009.06.009

Lean, H.H., and Smyth, R. (2009). Long memory in US disaggregated petroleum consumption: evidence from univariate and multivariate LM tests for fractional integration, Energ. Policy, 37(8), 3205-3211. http://dx.doi.org/10.1016/j.enpol.2009.04.017

Li, Y.F., Li, Y.P., Huang, G.H., and Chen, X. (2010). Energy and environmental systems planning under uncertainty-An inexact fuzzy-stochastic programming approach, Appl. Energ., 87(10), 
3189-3211. http://dx.doi.org/10.1016/j.apenergy.2010.02.030

Li, Y.P., Huang, G.H., Yang, Z.F., and Nie, S.L. (2009). 0-1 Piecewise linearization approach for interval-parameter nonlinear programming: application to environmental management under uncertainty, Can. J. Civil Eng., 36(6), 1071-1084.

Meng, M., and Niu, D.X. (2011). Annual electricity consumption analysis and forecasting of China based on few observations methods, Energ. Convers Manage., 52(2), 953-957. http://dx.doi. org/10.1016/j.enconman.2010.08.023

Muis, Z.A., Hashim, H., Manan, Z.A., Taha, F.M., and Douglas, P.L. (2010). Optimal planning of renewable energy-integrated electricity generation schemes with $\mathrm{CO}_{2}$ reduction target, Renew. Energ., 35(11), 2562-2570. http://dx.doi.org/10.1016/j.renene.2010.03.032

Nikolaidis, V.C., and Vournas, C.D. (2008). Design strategies for load-shedding schemes against voltage collapse in the Hellenic system, IEEE T. Power Syst., 23(2):582-591. http://dx.doi.org/10. 1109/TPWRS.2008.919242

Papachristos, S., and Skouri, K. (2003). An inventory model with deteriorating items, quantity discount, pricing and time-dependent partial backlogging, Int. J. Prod. Econ., 83(3), 247-256. http://dx. doi.org/10.1016/S0925-5273(02)00332-8

Porras, E, and Dekker, R. (2008). An inventory control system for spare parts at a refinery: an empirical comparison of different re-order point methods, Eur. J. Oper. Res., 184(1), 101-132. http:// dx.doi.org/10.1016/j.ejor.2006.11.008

Rempel H, Schmidt S, and Schwarz-Champera U. (2006). Reserves, Resources and Availability of Energy Resources 2006, Federal Institute for Geosciences and Natural Resources, BGR.

Rieksts, B.Q., and Ventura, J.A. (2010). Two-stage inventory models with a bi-modal transportation cost, Comput. Oper. Res., 37(1), 2031. http://dx.doi.org/10.1016/j.cor.2009.02.026

Rubin, E.S., Rao, A.B., and Chen, C. (2004). Comparative assessments of fossil fuel power plants with $\mathrm{CO}_{2}$ capture and sto- rage, Proc. of the seventh international conference on green- house gas control technologies, Vancouver.

Shen, Y.S., Tan, Z.F., Shen, X.L., Bai, J.J., Li, Q.Z. and Wang, S. (2012). Study of Energy Saving and Emission Reduction based on the OLAP Multi-Indicator Relational Model, J. Environ. Inform., 20(2), 115-122. http://dx.doi.org/10.3808/jei.201200225

Shin, H, and Benton, W.C. (2007). A quantity discount approach to supply chain coordination, Eur. J. Oper. Res., 180(2), 601-616. http://dx.doi.org/10.1016/j.ejor.2006.04.033

Suo, M.Q., Li, Y.P., and Huang, G.H. (2011). An inventory-theorybased interval-parameter two-stage stochastic programming model for water resources management, Eng. Optimiz., 43(9), 999-1018. http://dx.doi.org/10.1080/0305215X.2010.528412

Suo, M.Q., Li, Y.P., and Huang, G.H. (2012). Multicriteria decision making under uncertainty: An advanced ordered weighted averaging operator for planning electric power systems, Eng. Appl. Artif. Intel., 25(1), 72-81. http://dx.doi.org/10.1016/j.engappai.2011.08.0 07

Tripathy, S.C. (1997). Demand forecasting in a power system. Energ,
Convers Manage., 38(14), 1475-1481. http://dx.doi.org/10.1016/S 0196- 8904(96)00101-X

Tsao, Y.C., and Lu, J.C. (2012). A supply chain network design considering transportation cost discounts. Transport, Res. E-Log., 48(2), 401-414. http://dx.doi.org/10.1016/j.tre.2011.10.004

Tunc, M., Camdali, Ü., and Parmaksizoğlu, C. (2006). Comparison of Turkey's electrical energy consumption and production with some European countries and optimization of future electrical power supply investments in Turkey, Energ. Policy, 34(1), 50-59. http:// dx.doi.org/10.1016/j.enpol.2004.04.027

Wang, T.-Y., and Yang, Y.-H. (2009). A fuzzy model for supplier selection in quantity discount environments, Expert syst. Appl., 36 (10), 12179-12187. http://dx.doi.org/10.1016/j.eswa.2009.03.018

Wee, H.M., and Yang, P.C. (2004). The optimal and heuristic solutions of a distribution network, Eur. J. Oper. Res., 158(3), 626-632. http://dx.doi.org/10.1016/S0377-2217(03)00383-7

Wiszniewski, A. (2007). New criteria of voltage stability margin for the purpose of load shedding, IEEE T. Power Deliver., 22(3), 1367-1371. http://dx.doi.org/10.1109/TPWRD.2006.886772

WuAn Statistics Bureau (2011). WuAn energy supply and consumption, WuAn, Hebei, China [in Chinese].

Xia, C., Wang, J., and McMenemy, K. (2010). Short, medium and long term load forecasting model and virtual load forecaster based on radial basis function neural networks, Int. J. Elec. Power, 32(7), 743-750. http://dx.doi.org/10.1016/j.ijepes.2010.01.009

Xiong, J., Zhao, H.B., Zhang, C., Zheng, C.G., and Luh, P.B. (2012). Thermoeconomic operation optimization of a coal-fired power plant, Energy, 42(1), 486-496. http://dx.doi.org/10.1016/j.energy. 2012.03.020

Yang, N., and Wen, F.S. (2005). A chance constrained programming approach to transmission system expansion planning, Electr. Pow. Syst. Res., 75(2-3), 171-177. http://dx.doi.org/10.1016/j.epsr.2005. 02.002

Yang, Y.P., Guo, X.Y., and Wang, N.L. (2010). Power generation from pulverized coal in China, Energy, 35(11), 4336-4348. http:// dx.doi.org/10.1016/j.energy.2009.05.006

Yin, G.P. (2011). An analysis report on the social economic and environment in Hebei province in 2011, Hebei, China. Sponsored by environmental protection agency in Hebei province [in Chinese].

Zhang, H.Y. (2011). The Plan of main pollutant total emission reduction for WuAn in 2011, WuAn, Hebei, China. Sponsored by environmental protection bureau in WuAn [in Chinese].

Zhou, Q., Chan, C.W., and Tontiwachiwuthikul, P. (2011). Development of an Intelligent System for Monitoring and Diagnosis of the Carbon Dioxide Capture Process, J. Environ. Inform., 18(2), 75-83. http://dx.doi.org/10.3808/jei.201100201

Zhou, Y., Cheng, S.Y., Liu, L., and Chen, D.S. (2012). A coupled MM5-CMAQ modeling system for assessing effects of restriction measures on PM10 pollution in Olympic City of Beijing, China, $J$. Environ. Inform., 19(2), 120-127. http://dx.doi.org/10.3808/jei.201 200214 